\title{
UNA REVISIÓN DEL CONCEPTO DE IMPUTABILIDAD DESDE LAS CIENCIAS DE LA SALUD. SU COMPATIBILIDAD CON LA REGULACIÓN PENAL VIGENTE ${ }^{1}$
}

\author{
Itzíar Casanueva Sanz
}

\begin{abstract}
Sumario: 1. Introducción. 2. LA IMPUTABILIDAD. 2.1. La defensa de un indeterminismo limitado en relación con el comportamiento humano. Sus implicaciones en el concepto de imputabilidad. 2.2. Las funciones psíquicas y el proceso volitivo. 2.2.1. Las funciones psíquicas. 2.2.2. El proceso volitivo. 2.3. Las «condiciones» objeto de análisis en la imputabilidad. 2.4. Especial referencia a los factores socioculturales. 3. LA IMPUTABILIDAD EN EL CÓDIGO PENAL DE 1995. COMPATIBILIDAD CON EL CONCEPTO DE IMPUTABILIDAD PROPUESTO. 3.1. Capacidad para comprender la ilicitud del hecho. 3.1.1. Capacidad para comprender. 3.1.2. La ilicitud del hecho. 3.1.3. Funciones psíquicas que intervienen en el proceso de comprensión de la ilicitud del hecho. 3.2. Capacidad para actuar conforme a esa comprensión. 3.3. Compatibilidad con el concepto de imputabilidad propuesto en esta investigación. 3.4. Algunas críticas no compartidas.
\end{abstract}

\section{INTRODUCCIÓN}

La imputabilidad puede definirse, en una primera aproximación, como «aquella categoría dogmática mediante la cual se establecen las condiciones

${ }^{1}$ Este artículo tiene su origen en los capítulos segundo y tercero de la tesis defendida por Itzíar Casanueva Sanz el 5 de julio de 2013 en la Universidad de Deusto y titulada «La imputabilidad, el consumo de drogas y su regulación jurídico-penal. Una revisión desde las ciencias de la salud». 
que debe tener un sujeto para que le sea atribuible penalmente el hecho antijurídico que ha realizado» ${ }^{2}$.

A partir de aquí, las opiniones doctrinales sobre cuál es el fundamento y el contenido de esta categoría son muy divergentes; incluso hay preceptos del Código Penal de los cuáles se discute si afectan a esta categoría del delito o a otra ${ }^{3}$.

Sí existe cierto consenso en considerar que la imputabilidad se refiere, al menos, a condiciones de carácter psíquico, es decir, al estado de las facultades o capacidades psíquicas del sujeto. Facultades o capacidades que son objeto directo de estudio de ciencias ajenas al Derecho como la Psicología, Psiquiatría, Psicopatología, etc., a las que, de manera genérica y sin ninguna pretensión de rigor científico se va a aludir con la expresión «ciencias de la salud»o «ciencias del comportamiento humano».

Los jueces y tribunales solicitan de manera general la opinión de peritos expertos en estas materias para poder determinar si una persona es imputable, inimputable o si su imputabilidad está disminuida pero, sin embargo, son muchos los estudios doctrinales sobre esta categoría del delito, así como sobre las circunstancias eximentes o atenuantes recogidas en el Código Penal relacionadas con la misma, que no aluden a dichas ciencias, o lo hacen sólo de manera muy somera y poco rigurosa.

Esta manera de proceder no es adecuada, puesto que los juristas poco podemos decir sobre el comportamiento humano, las facultades y capacidades psíquicas de los individuos o sus alteraciones, si no es tomando en consideración las aportaciones y conocimientos de los profesionales expertos en la materia.

Partiendo de este convencimiento, la pretensión de este artículo es revisar el concepto y contenido de la imputabilidad teniendo como punto de referencia las aportaciones y conocimientos actuales de las ciencias antes mencionadas. Esto no quiere decir que haya que trasladar automáticamente al Derecho Penal dichas contribuciones, pero sí que hay que tenerlos en cuenta y valorarlos de manera más adecuada.

La exposición que sigue se va a dividir en dos partes. En un primer momento se va a proponer un concepto de imputabilidad acorde con las exigencias que se acaban de mencionar concretando lo máximo posible cuáles son

${ }^{2}$ Fonseca Morales, G. M.: Exención y atenuación de la responsabilidad criminal por anomalía o alteración psíquica. Especial referencia a su tratamiento jurisprudencial, tesis doctoral, Granada, 2007, p. 61. Pueden verse otras definiciones en FONSECA Morales, G. M.: Exención y atenuación de la responsabilidad criminal..., ob. cit., pp. 61 y ss.; Núñez Gaitán, M ${ }^{\mathrm{a}}$ C./López Miguel, M ${ }^{\mathrm{a}} \mathrm{J}$.: «Psicopatología y delincuencia. Implicaciones en el concepto de imputabilidad», RECPC, n. 11, 2009, http://criminet.ugr. es/recpc, ob. cit., p. 3; Orts Berenguer, E./GonzÁlez Cussac, J. L.: Compendio de Derecho Penal. Parte General, $3^{\text {a }}$ ed, Tirant lo Blanch, Valencia, 2011, p. 305; SÁnchez Yllera, I.: «Artículo 20.1», en Vives Antón, T. S. (coord.) Comentarios al Código Penal de 1995, Vol. I, Tirant lo Blanch, Valencia, 1996, p. 113.

3 Así, por ejemplo, en relación con la atenuante del art. 21.2 del Código Penal. 
los aspectos relevantes en el análisis de esta categoría del delito y, en un segundo momento, se va a plantear la compatibilidad de dicho concepto con el que se desprende de la regulación penal.

\section{LA IMPUTABILIDAD}

En este apartado se va a ir configurando paso a paso un concepto de imputabilidad que incorpore los conocimientos actuales de las ciencias de la salud. En primer lugar, se intentará concretar cuál es el fundamento de esta categoría del delito; en segundo lugar se hará referencia a las funciones psíquicas que pueden diferenciarse en la psique humana, así como al denominado proceso volitivo. Finalmente, se integrará todo ello para ofrecer el concepto y contenido de la imputabilidad que se considera más adecuado.

\subsection{La defensa de un indeterminismo limitado en relación con el comportamiento humano. Sus implicaciones en el concepto de imputabilidad}

En esta investigación se entiende que la imputabilidad es uno de los elementos de la culpabilidad ${ }^{4}$ de manera que cuál sea el contenido y fundamento de la imputabilidad va a depender, en gran medida, del contenido y fundamento de la culpabilidad, cuestiones estas que han sido y siguen siendo vivamente discutidas en la doctrina.

No es este el momento ni el lugar, por exceder con mucho las dimensiones de este trabajo ${ }^{5}$, para hacer un examen exhaustivo de la evolución que

${ }^{4}$ De la misma opinión, entre otros: CoBo Del Rosal, M./Vives AnTón, T. S.: Derecho Penal. Parte General, $5^{\text {a }}$ ed., Tirant lo Blanch, Valencia, 1999, p. 581; Cuello Contreras, J./Mapelli Caffarena, B: Curso de Derecho Penal. Parte General, Tecnos, Madrid, 2011, p. 101; Fonseca Morales, G. M.: Exención y atenuación de la responsabilidad..., ob. cit., p. 40; Melendo Pardos, M: «El delito como conducta reprobable I: La imputabilidad, su exclusión y su graduación», en GIL GIL, A. et. al.: Curso de Derecho Penal. Parte General, Dykinson, 2011, p. 568; Muñoz Conde, F./García Arán, M.: Derecho Penal. Parte Gene$\mathrm{ral}, 8^{\mathrm{a}}$ ed. revisada y puesta al día, Tirant lo Blanch, Valencia, 2010, p. 358. Por el contrario, algunos autores mantienen que se trata de un presupuesto de la culpabilidad: BLANCO LOZANo, C.: Tratado de Derecho Penal español. Tomo I. El sistema de la Parte General. Volumen 2. La estructura del delito, Bosch, Barcelona, 2005, p. 187; Cerezo Mir, J.: Curso de Derecho Penal español. Parte General. Vol. III. Teoría jurídica del delito/2, Tecnos, Madrid, 2005, p. 50. Puede verse un recorrido histórico sobre la consideración de la imputabilidad como elemento o presupuesto de la culpabilidad en Fonseca Morales, G. M.: Exención y atenuación de la responsabilidad criminal..., ob. cit., pp. 36 y ss.

${ }_{5}$ Para hacer un análisis de la evolución que han sufrido estos conceptos a lo largo de la historia pueden consultarse, entre otros: LÓPEZ BARJA DE QUIROGA, J.: «Aproximación a la culpabilidad como elemento del delito. Libre albedrío y determinismo. Finalismo. Funcionalismo. Evolución del concepto dogmático», en MARTínEZ ARrIETA, A. (dir.): Psiquiatría Criminal 
han sufrido estas categorías del delito ni de las distintas posturas existentes en la actualidad, pero sí resulta necesario una visión general de los términos en los que se plantea actualmente esta discusión.

Simplificando (quizá en exceso), se puede señalar que, en la actualidad son básicamente dos las teorías, o más bien grupos de teorías, que, en nuestra doctrina, intentan explicar el fundamento de la imputabilidad ${ }^{6}$.

y comportamientos violentos, Cuadernos de Derecho Judicial, n. 8, CGPJ, Madrid, 2005, pp. 16 y ss.; De Llera SuÁrez-BÁRCENA, E.: «Imputabilidad y fines de la pena. La relación de los efectos psicológicos previstos en el art. $20 \mathrm{y}$ en el art. $60 \mathrm{CP}$ », en PANTOJA GARCíA, F./BuenO ARÚs, F. (dirs.): Actual doctrina de la imputabilidad penal, Estudios de Derecho Judicial, n. 110, CGPJ, Madrid, 2007, pp. 267 y ss.; DíEz RIPOLLÉS, J. L.: «Aspectos generales de la imputabilidad», en PANTOJA GARCÍA, F./BuENO ARÚs, F. (dirs.): Actual doctrina de la imputabilidad penal, Estudios de Derecho Judicial, n. 110, CGPJ, Madrid, 2006, pp. 16 y ss.; GARCÍA GARCíA, J.: Drogodependencias y justicia penal, Ministerio de Justicia, Madrid, 1999, pp. 127 y ss.; JoSHI JUBERT, U.: Anomalía y alteración psíquica en el Código Penal español, Difusión jurídica, Madrid, 2009, pp. 19 y ss.; MiR PuIG, S.: Derecho Penal. Parte General, $9^{\mathrm{a}}$ edición, Reppertor, Barcelona, 2011, pp. 535 y ss.; PADIlla Alba, H. R.: «El fundamento de la capacidad de culpabilidad: el art. $20.1^{\circ}$ del Código Penal», en CASAdo Raigón, R./Gallego DOMínguez, I. (coords.): Personalidad y capacidad jurídica, Vol. 2, Servicio de publicaciones de la Universidad de Córdoba, Córdoba, 2005, pp. 949 y ss.; EL MISMO: Exención y atenuación de la responsabilidad penal por consumo de droga, Comares, Granada, 2001, pp. 81 y ss.; PÉREZ-CURIEL CECCHINI, J.: Tratamiento penal del drogodependiente. Análisis práctico de las eximentes y atenuantes del Código Penal de 1995, Forum, Oviedo, 1999, pp. 54 y ss.; QuINTERo Olivares, G.: Parte General del Derecho Penal, $4^{\mathrm{a}}$ ed., Aranzadi, Cizur Menor, 2010, pp. 401 y ss.; SuÁrez-Mira Rodríguez, C. (coord.): Manual de Derecho Penal. Tomo I. Parte General, $6^{\text {a }}$ ed., Thomson Reuters, Cizur Menor, 2011, pp. 177 y ss.; EL MISMO: La imputabilidad del consumidor de drogas, Tirant lo Blanch, Valencia, 2000, pp. 23 y ss.; UrRUELA MorA, A.: Imputabilidad penal y anomalía o alteración psíquica, Comares, Granada, 2003, pp. 7 y ss.

${ }^{6}$ A estas dos orientaciones se refieren también, entre otros: CASTELlÓ NICÁs, N.: «Exención y atenuación de la responsabilidad criminal (arts. 20.1 $\left.1^{\mathrm{o}}, 20.2^{\mathrm{o}}, 21.1^{\mathrm{a}}, 21.2^{\mathrm{a}}\right) »$, en MORILLAS Cueva, L. (coord.): Estudios jurídico-penales y político-criminales sobre tráfico de drogas y figuras afines, Dykinson, Madrid, 2003, pp. 302 y ss.; DíEZ RIPOLLÉs, J. L.: «Aspectos generales de la imputabilidad», ob. cit., pp. 15 y ss.: FonseCA MorALES, G. M.: Exención y atenuación de la responsabilidad criminal..., ob. cit., pp. 40 y ss.; JOSHI JUBERT, U.: Anomalía y alteración psíquica ..., ob. cit., pp. 34 y 35; LUZÓN PEÑA, D. M.: «Libertad, culpabilidad y neurociencias», InDret, 3/2012, www.indret.com, pp. 8 y ss.; MARTín LORENZO, M.: La exculpación penal. Bases para una atribución legítima de responsabilidad penal, Tirant lo Blanch, Valencia, 2009, pp. 45 y ss.; SANZ MorÁn, A. J.: «Algunas consideraciones sobre culpabilidad y pena», en DíEZ RIPOLlÉs, J. L. et. al. (eds.): La ciencia del Derecho Penal ante el nuevo siglo. Libro Homenaje al Profesor Doctor Don José Cerezo Mir, Tecnos, Madrid, 2003, pp. 147 y ss.

No obstante, algunos autores se apartan de estas dos líneas principales. A título de ejemplo, podemos citar a: Bustos Ramírez, J. J./HormazÁBal MalaréE, H.: Lecciones de Derecho Penal. Parte General, Trotta, Madrid, 2006, pp. 437 y ss.; Los MISMOS: Nuevo sistema de Derecho Penal, Trotta, Madrid, 2004, pp. 125 y ss.; GómEZ BeníteZ, J. M.: «Sobre lo interno y lo externo, lo individual y lo colectivo en el concepto penal de culpabilidad», en SILVA SÁNCHEZ, J. M. (ed.): Política criminal y nuevo Derecho Penal. Libro Homenaje a Claus Roxin, Bosch, Barcelona, 1997, p. 274; Gomez-JARA DíEZ, C.: «Teoría de sistemas y Derecho Penal: 
En primer lugar, la que podemos denominar «concepción normativa» de la culpabilidad ${ }^{7}$ entiende este elemento del delito como un juicio de reproche o de atribución que se hace a un sujeto que lleva a cabo un hecho ilícito cuando podía haber actuado conforme al ordenamiento, es decir, tenía capacidad para haber obrado de otro modo. Esta manera de entender la culpabilidad se fundamenta en el libre albedrío, en el hecho de que las personas, en condiciones «normales», podemos actuar libremente, es decir, podemos decidir hacer una cosa u otra y actuar según lo decidido. Precisamente, es posible llevar a cabo ese reproche en el que consiste la culpabilidad porque pudiendo actuar conforme a derecho en un momento concreto, el sujeto no lo hace y «libremente» decide llevar a cabo el hecho antijurídico ${ }^{8}$.

El segundo bloque de teorías pueden agruparse bajo la denominación de «teorías de la motivabilidad». Sus defensores consideran que el libre albedrío no existe o, al menos, es imposible demostrar empíricamente su existencia y menos aún probar que un sujeto en un momento concreto había podido actuar de otra manera, es decir que ha sido libre en relación con el hecho que se le imputa 9 . Siendo esto así, la culpabilidad no puede basarse en algo indemostrable como el libre albedrío.

culpabilidad y pena en una teoría constructivista del Derecho Penal», en GómEZ-JARA DíEZ, C. (ed.): Teoría de sistemas y Derecho Penal. Fundamentos y posibilidades de aplicación, Comares, Granada, 2005, pp. 386 y 427; GONZÁLEZ-RIVERO, P.: «Imputación jurídico-penal en estado de defecto», en LóPez BarJa de Quiroga, J./Zugaldía Espinar, J. M. (coords.): Dogmática y ley penal. Libro Homenaje a Enrique Bacigalupo, Tomo I, Instituto Universitario de Investigación Ortega y Gasset-Marcial Pons, Madrid, 2004, pp. 263 y 264.

7 LuZÓn PeÑA, D. M.: «Libertad,...», ob. cit., p. 8, señala que actualmente este grupo de teorías son las mayoritarias.

8 Berdugo Gómez de la Torre, I. et al.: Curso de Derecho Penal. Parte General. $2^{\mathrm{a}}$ ed., Ediciones Experiencia, Barcelona, 2010, p. 320; Cerezo Mir, J.: Curso de Derecho Penal español. Parte General..., ob. cit., p. 114; CoBo Del Rosal, M./Vives Antón, T.: Derecho Penal. Parte General, ob. cit., p. 535; Landecho Velasco, C. M./Molina BlázQuez, C.: Derecho Penal español. Parte General, $8^{\mathrm{a}}$ ed., Tecnos, Madrid, 2010, p. 348; ORTS BERenguer, E./González Cussac, J. L.: Compendio de Derecho Penal. Parte General, ob. cit., p. 301; Zugaldía ESPINAR, J. M.: «Delitos de acción. La culpabilidad (I)», en ZugaLdía Espinar, J. M. (dir.)/Moreno-Torres Herrera, M. R. (coord.): Fundamentos de Derecho Penal. Parte General, $4^{\mathrm{a}}$ ed., Tirant lo Blanch, Valencia, 2010, p. 330. Un análisis detenido de la evolución de las concepciones normativas de la culpabilidad puede verse en MELENDO PARDOS, M.: El concepto material de culpabilidad y el principio de inexigibilidad. Sobre el nacimiento y evolución de las concepciones normativas, Comares, Granada, 2002.

9 Son muchos los autores que recurren a la famosa argumentación de ENGISCH según la cual la única forma de comprobar esa posibilidad sería «repetir varias veces las mismas condiciones bajo las que se ha tomado una determinada decisión de voluntad y observar si ésta se repite también en todos los casos. Un experimento así es imposible porque no es posible reproducir con exactitud las mismas condiciones existentes en un momento pasado en cualquier caso, siempre habría un factor distinto: el paso del tiempo determinará en el sujeto de la decisión una acumulación de recuerdos en su mente y una serie de modificacio- 
A partir de aquí reinterpretan el concepto de culpabilidad a la luz de las necesidades preventivas; el fin de las normas penales es evitar la comisión de delitos a través de su función motivadora, de manera que un sujeto será culpable si puede ser motivado por los mandatos normativos, si tiene capacidad para ser motivado, centrando el análisis en la motivabilidad, en la accesibilidad del sujeto al mandato normativo ${ }^{10}$.

$\mathrm{Si}$, como se ha señalado, la imputabilidad es un elemento de la culpabilidad, el fundamento de esta última condicionará el fundamento y contenido de la primera. Así, los partidarios de un concepto normativo de culpabilidad consideran que un sujeto es imputable si en el momento de los hechos podía haber evitado la conducta, era libre para actuar de otro modo y, por el contrario, será declarado inimputable si, como consecuencia de algún tipo de afectación en sus facultades psíquicas, no gozaba de dicha libertad, de manera que lleva a cabo el hecho antijurídico sin capacidad para actuar de otro modo, sin capacidad para comprender la ilicitud de lo realizado o para actuar conforme a esa comprensión ${ }^{11}$.

Los defensores de las teorías de la motivabilidad, por su parte, configuran la imputabilidad como la capacidad de ser motivado por las normas, considerando inimiputable al sujeto que en el momento de llevar a cabo el hecho ilícito no podía motivarse por las normas, es decir, éstas no podían desplegar sus efectos motivadores sobre él ${ }^{12}$.

nes en su cuerpo que lo enfrentarían a cada nueva decisión en unas condiciones distintas». Por todos, MIR PUIG, S.: «La imputabilidad en Derecho Penal», en ORTEGA-MonASTERIO, L. et al.: Psicopatología jurídica y forense, Vol. I, PPU, Barcelona, 1991, p. 157.

${ }^{10}$ Defienden esta postura, entre otros autores: GIMBERNAT ORDEIG, E.: Introducción a la Parte General del Derecho Penal, Universidad Complutense. Facultad de Derecho, 1979, p. 69; MARTíNEZ GARAY, L.: La imputabilidad penal: concepto, fundamento, naturaleza jurídica y elementos, Tirant lo Blanch, Valencia, 2005, p. 177; MIR PUIG, S.: «La imputabilidad en Derecho Penal», ob. cit., p. 158; Muñoz Conde, F./GARCÍA ARÁN, M.: Derecho Penal. Parte General, ob. cit., p. 350; Octavio de Toledo y Ubieto, E./Huerta Tocildo, S.: Derecho Penal. Parte General. Teoría Jurídica del Delito, $2^{\mathrm{a}}$ ed., Editor Rafael Castellanos, Madrid, 1986, p. 295; SANZ MorÁN, A. J.: "Algunas consideraciones...», ob. cit., p. 155; SUÁREZ-MIRA RoDRÍGUEZ, C.: La imputabilidad del consumidor de drogas, Tirant lo Blanch, Valencia, 2000, pp. 73 y 74.

11 Berdugo de la Torre, I. et al.: Curso de Derecho Penal. Parte General, ob. cit., p. 320; FonseCa Morales, G. M.: Exención y atenuación en la responsabilidad criminal..., ob. cit., pp. 42 y ss.; Romeo CaSABona, C. M.: Genética, Biotecnología y Ciencias Penales, Pontificia Universidad Javeriana, Bogotá, 2009, p. 417; SubiJana ZunZunEGui, I. J.: «El Código Penal ante la enfermedad mental y la peligrosidad», Revista del Poder Judicial, n. 89, 2009, p. 219.

12 Fonseca Morales, G. M.: Exención y atenuación en la responsabilidad criminal..., ob. cit., pp. 42 y ss.; Romeo CASABONA, C. M.: Genética ..., ob. cit., p. 417; SUBIJANA ZunZunegUi, I. J.: «El Código Penal ante la enfermedad mental y la peligrosidad», ob. cit., p. 219. 
Como se ha apuntado, en la base de esta diferencia de opiniones se encuentra la polémica sobre la existencia del libre albedrío y la posibilidad de fundamentar en el mismo la imputabilidad, la culpabilidad y, el última instancia, la responsabilidad penal. ¿Podemos los seres humanos elegir, decidir y actuar en función de lo decidido? O, por el contrario, ¿todas nuestras decisiones y actos se deben únicamente a la interacción de factores internos y externos sin que nuestra voluntad juegue papel alguno? ¿Quizá se puede defender una postura intermedia? Nos encontramos ante la «vieja», aunque todavía no resuelta polémica determinismo-indeterminismo.

En este trabajo se defiende ${ }^{13}$ una libertad limitada, un «indeterminismo limitado» en relación con el actuar humano ${ }^{14}$. Es decir, se entiende que el

${ }^{13}$ Un estudio en profundidad de los argumentos sociológicos, científicos y jurídicos que se utilizan en la doctrina para decantarse a favor o en contra de la existencia del libre albedrío excede el objetivo de este artículo. Para un análisis más detenido de los mismos, pueden consultarse, entre otras, las siguientes referencias bibliográficas: CARBONELL MATEU, J. C.: «Sobre la imputabilidad en Derecho Penal español», en AAVV: La imputabilidad en general en el Derecho Penal, Cuadernos de Derecho Judicial, n. 17, CGPJ, Madrid, 1993, pp. 14 y ss.; DEMETRIO CRESPO, E.: «Libertad de voluntad, investigación sobre el cerebro y responsabilidad penal. Aproximación a los fundamentos del moderno debate sobre Neurociencias y Derecho penal», InDret, 2/2011, www.indret.com; DíEZ RIPOLLÉS, J. L.: «Aspectos generales de la imputabilidad», ob. cit., pp. 20 y 21; FÄH, L. et al.: «¿Un nuevo determinismo?», en BuEno ARÚs, F. et. al. (dirs.): Derecho Penal y Criminología como fundamento de la política criminal. Estudios en homenaje al profesor Alfonso Serrano Gómez, Dykinson, 2006, pp. 228 y ss.; García García, J.: Drogodependencias y justicia penal, ob. cit., pp. 162 y ss.; HUERTAS, J. A.: «Las teorías de la motivación desde el ámbito de lo cognitivo y lo social», en Palmero, F./Martínez SÁnchez, F. (coords.): Motivación y emoción, Mc Graw Hill, Madrid, 2008, pp. 79 y ss.; JiMÉNEZ SÁNCHEZ, M. P.: «Motivación intrínseca. Competencia, autodeterminación y control», en FERNÁNDEZ ABASCAL, E. G. et. al.: Emoción y motivación. La adaptación humana. Volumen II, Centro de Estudios Ramón Areces, Madrid, 2003, pp. 799 y ss.; Joshi JUBERT U.: Anomalía y alteración psíquica..., ob. cit., pp. 61 y ss.; LANDECHO Velasco, C. M./Molina Blázquez, C.: Derecho Penal español. Parte General, ob. cit., pp. 350 y ss.; LuZÓN PeÑA, D. M.: «Libertad...», ob. cit., pp. 33 y ss.; MARTínez GARAY, L.: La imputabilidad penal:..., ob. cit., pp. 132 y ss., 411 y ss.; MolinA FernándeZ, F.: «Presupuestos de la responsabilidad jurídica (análisis de la relación entre libertad y responsabilidad)», ADPCP, Tomo LIII, 2000, pp. 227 y ss.; Morales Prats, F.: «Precisiones conceptuales en torno a la culpabilidad: convenciones normativas y función individualizadora», en CEREzo Mir, J. et. al. (eds.): El nuevo Código Penal: presupuestos y fundamentos. Libro Homenaje al Profesor Doctor Don Ángel Torío López, Comares, Granada, 1999, pp. 173 y 174; PÉREZ MANZANO, M.: «Fundamento y fines del Derecho penal. Una revisión a la luz de las aportaciones de la neurociencia», InDret, 2/2011, www.indret.com; PERIS RIERA, J. M.: «Condicionantes genéticas y responsabilidad penal: ¿Hacia un renacimiento de los planteamientos deterministas fundamentadores de la culpabilidad?», en DíEZ RIPOLLÉs, J. L. et. al. (eds.): La ciencia del Derecho Penal ante el nuevo siglo. Libro Homenaje al Profesor Doctor Don José Cerezo Mir, Tecnos, Madrid, 2003, pp. 94 y ss.; Romeo Casabona, C. M.: «Genética...», ob. cit., pp. 401 y ss.; UrRUela Mora, A.: Imputabilidad penal..., ob. cit., pp. 56 y ss.

${ }_{14}$ La misma terminología, «indeterminismo limitado», utiliza también ROMEO CASABONA, C. M.: Genética..., ob. cit., p. 411. Algunos autores, en lugar del adjetivo «limitado», re- 
comportamiento humano está condicionado por múltiples factores internos y externos pero, a pesar de ello, si las circunstancias en las que se encuentra el sujeto son normales, existe siempre la posibilidad de valorar dichos condicionamientos y decidir en un sentido u otro, es decir, de elegir y de actuar en consecuencia ${ }^{15}$. El comportamiento humano, por lo tanto, no está vinculado de forma inexorable al instinto ni a aconteceres científico-causales, sino que, a pesar de la existencia de factores que inciden en el mismo, el individuo ante una situación concreta, tiene un campo de juego, un marco de libertad en el cual interactúa ${ }^{16}$. Al afirmar que un acto es libre lo que se indica es que la decisión final no es solo consecuencia de dichos factores, sino que el propio sujeto introduce algún factor ex novo en él, la decisión última es suya, no está totalmente condicionada de manera causal por dichos factores ${ }^{17}$.

curren a «relativo» (SuÁREZ-MiRA RodríGuEZ, C. (coord.): Manual de Derecho Penal. Tomo I. Parte General, ob. cit., p. 176) o «condicionado» (MANTOVANI, F.: «Libertad, responsabilidad jurídica y genes», en Arroyo ZAPATERo, L. A./BERdugo GómeZ DE LA TORRe, I. (dirs.): Homenaje al Dr. Marino Barbero Santos In Memoriam, Vol. I, Ediciones de la Universidad de Castilla-La Mancha-Ediciones Universidad de Salamanca, Cuenca, 2001, p. 1138).

15 Se muestran partidarios de la libertad de voluntad, del «poder obrar de otro modo», de la libertad para tomar la decisión de delinquir o abstenerse de ello como esencia de la imputabilidad, entre otros, CARBOnEll MAteU, J. C.: «Sobre la imputabilidad en Derecho Penal español», ob. cit., pp. 20 y 21; DE LA CUESTA ARZAMENDI, J. L.: «Imputabilidad y nuevo Código Penal», en Cerezo Mir, J. et. al. (eds.): El nuevo Código Penal: presupuestos y fundamentos. Libro Homenaje al Profesor Doctor Don Ángel Torí López, Comares, Granada, 1999, p. 301; DiÉz RIPOLLÉS, J. L.: «Aspectos generales de la imputabilidad», ob. cit., p. 22; FÄH, L. et al.: «¿Un nuevo determinismo?», ob. cit., p. 236; FONSECA MoRALES, G. M.: Exención y atenuación de la responsabilidad criminal..., ob. cit., pp. 77 y 78; García García, J.: Drogodependencias y justicia penal, ob. cit., p. 132; Higuera GuIMERÁ, J. F.: «La imputabilidad en los sujetos activos de la violencia doméstica y de género (Referencia a la práctica de la prueba pericial-psiquiátrica)», Revista General de Derecho Penal, n. 3, 2005. www.iustel.com, p. 33; LuZÓn PeÑA, D. M.: «Libertad,...», ob. cit., pp. 5, 14, 32; PRATS CANUT, J. M.: «La culpabilidad: principio y categoría dogmática», en Quintero Olivares, G./Morales Prats, F. (coords.): El nuevo Derecho Penal español. Estudios penales en memoria del Profesor José Manuel Valle Muñiz, Aranzadi, Navarra, 2001, p. 638; Quintero Olivares G.: Parte General del Derecho Penal, ob. cit., p. 427; SuÁrez-Mira Rodríguez, C. (coord.): Manual de Derecho Penal. Tomo I. Parte General, ob. cit., p. 179; StAmPa BRAun, J. M.: «Culpabilidad penal y genoma humano», en LóPez BarJa de Quiroga, J./Zugaldía Espinar, J. M. (coords.): Dogmática y ley penal. Libro Homenaje a Enrique Bacigalupo, Tomo I, Instituto Universitario de Investigación Ortega y Gasset-Marcial Pons, Madrid, 2004, p. 900; URRUELA MoRA, A.: Imputabilidad penal..., ob. cit., p. 23.

${ }^{16}$ Morales Prats, F.: «Precisiones conceptuales...», ob. cit., p. 174; UrRUela Mora, A.: Imputabilidad penal..., ob. cit., p. 71.

17 A esta libertad se refieren LANDECHO Velasco/Molina BLÁZQueZ cuando afirman que se trata de una libertad interna libre de coacciones que impidan su ejercicio, considerando que los motivos juegan un papel importante, pero no deciden, porque si no el acto dejaría de ser libre. En Derecho Penal español. Parte General, ob. cit., pp. 354 y 355. 
Partiendo de la definición de imputabilidad ofrecida al inicio de este artículo, podemos completarla señalando que es aquella categoría dogmática mediante la cual se establecen las condiciones que debe tener un sujeto para poder afirmar que en el momento de los hechos podía haber actuado de otro modo, era libre para actuar conforme a derecho pero libremente, voluntariamente decidió vulnerar y vulneró una norma penal. Por el contrario, un individuo será inimputable si no pudo evitar el hecho antijurídico, si no era libre para llevar a cabo un hecho distinto del ilícito realizado.

Pero esta definición no es suficiente, todavía hay que profundizar más en el concepto de imputabilidad porque, ¿a qué «condiciones» se refiere esta categoría del delito? ¿qué tipo de «condiciones» son las que deben ser analizadas? Para responder a esta pregunta es necesario dar algunos pasos más.

\subsection{Las funciones psíquicas y el proceso volitivo}

En este apartado se va a hacer referencia a las funciones psíquicas que pueden diferenciarse en la psique humana, así como al denominado «proceso volitivo». Aunque puede parecer un extraño paréntesis en la exposición, el lector va a «descubrir» enseguida la importancia de este epígrafe y su relevancia a la hora de configurar el contenido de la imputabilidad.

\subsubsection{Las funciones psíquicas}

Para desarrollar este epígrafe vamos a «asomarnos» al mundo de las ciencias de la salud y, en concreto, a la Psicopatología ${ }^{18}$ que estudia los signos y síntomas de la enfermedad mental, de los trastornos mentales, siendo la base fundamental sobre la que asentar posteriormente una categoría diagnóstica o una acción terapéutica. Esta ciencia, para llevar a cabo este estudio, diferencia y analiza separadamente las funciones psíquicas del ser humano y establece una serie de reglas y de conceptos generales sobre ellas ${ }^{19}$.

Como señala Oros MURUZABAL, «la actividad psíquica es un todo, complejo pero unitario e indivisible en partes», por eso, «en verdadero rigor

18 Algunos autores consideran que es parte de la Psicología (GisBert Grifo, M. S. et al.: Glosario de Psiquiatría Forense para médicos y juristas, Masson, Barcelona, 1995, p. 167), otros parte de la Psiquiatría (CARrasco Gómez, J. J./Maza Martín, J. M.: Tratado de Psiquiatría legal y forense, $4^{\mathrm{a}}$ ed., La Ley-Actualidad, Madrid, 2010, p. 91) y otros una ciencia en sí misma (CABrera Forneiro, J./Fuertes Rocañín, J. C: Psiquiatría y Derecho: dos ciencias obligadas a entenderse. Manual de Psiquiatría Forense, Cauce Editorial, Madrid, 1997, p. 119.).

19 Cabrera Forneiro, J./Fuertes Rocañín, J. C: Psiquiatría y Derecho: ..., ob. cit., p. 119; García-Pablos De Molina, A.: Introducción al Derecho Penal, 4 a ed., Centro de Estudios Ramón Areces, Madrid, 2006, p. 715; GisBert Grifo, M. S. et al.: Glosario de Psiquiatría Forense..., ob. cit., p. 167. 
científico no deberíamos dividirla, fragmentarla», porque al hacerlo «la desnaturalizamos». A pesar de ello, como indica este autor, estas divisiones y fragmentaciones se llevan a cabo por necesidades didácticas y de investigación aunque nunca se puede perder de vista que todos los procesos psíquicos están íntimamente unidos entre sí $^{20}$.

Teniendo en cuenta esta advertencia y tomando como referencia las aportaciones de la Psicopatología, se suele hacer, siguiendo un orden alfabético, la siguiente enumeración de funciones y capacidades psíquicas: la afectividad, la atención, la conciencia, la inteligencia, la memoria, el pensamiento, la percepción y la voluntad. ${ }^{21}$

A continuación se va a hacer una breve referencia a estas funciones cuya principal finalidad es que el lector repare en la estrecha vinculación existente entre todas ellas de modo que la alteración de una puede afectar seriamente a otra u otras ${ }^{22}$.

${ }^{20}$ Oros Muruzabal, M.: «La voluntad», Revista Española de Medicina Legal, n. 70-71, enero-junio, 1992, p. 107.

${ }^{21}$ La mayoría de los autores consultados, si bien con algunas variaciones, siguen esta clasificación. En este sentido, pueden consultarse las referencias bibliográficas incluidas en las notas a pie de este apartado.

22 Para profundizar en el estudio de cuáles son las alteraciones de cada una de las funciones puede consultarse, entre otros: Fuertes Rocañín, J. C./CABRERA ForneIro, J.: La salud Mental en los Tribunales. Manual de Psiquiatría Forense y Deontología Profesional, $2^{\mathrm{a}}$ ed., ARÁN, Madrid, 2007, pp. 100 y ss.; CARRASCO GóMEZ, J. J./MAZA MARTín, J. M.: Tratado..., ob. cit., pp. 97 y ss.; Eguíluz URUChURTU, I. et al.: «Psicopatología de la memoria», en Eguíluz URuchurtu, I./SEgarra Echebarría, R. (dirs.): Introducción a la Psicopatología, Ars Medica, Barcelona, 2005, pp. 55 y ss.; GArcía BlázQuez, M.: Análisis médico-legal de la imputabilidad en el Código Penal de 1995 (un análisis médico-legal del art. 20.1 y 20.2), Comares, Granada, 1997, 79 y ss.; GISBERT GRIFO, M. S. et al: Glosario de Psiquiatría Forense..., ob. cit., p. 64; GuAdILla FERnÁNDEZ, M. L. et al.: «Psicopatología de la percepción», en Eguíluz URUChurtu, I./SEgarra Echebarría, R. (dirs.): Introducción a la Psicopatología, Ars Medica, Barcelona, 2005, pp. 89 y ss.; Higueras Aranda, A. et al.: "Trastornos formales y del control del pensamiento», en Eguíluz URUCHURTU, I./ SEgarra Echebarría, R. (dirs.): Introducción a la Psicopatología, Ars Medica, Barcelona, 2005, pp. 144 y ss.; Marcó Ribé, J.MArtí Tusquets, J. L.: Psiquiatría Forense, $2^{\mathrm{a}}$ ed., ESPAXS, Barcelona, 2002, pp. 84 y ss.; MuÑoz DomíngueZ, P. et. al.: «Psicopatología de la conciencia», en Eguíluz URUCHURTU, I./SEgARRA ECHEBARRÍA, R. (dirs.): Introducción a la Psicopatología, Ars Medica, Barcelona, 2005, pp. 17 y ss.; OJEDA DEL Pozo, N. et al.: «Psicopatología de la atención», en Eguíluz Uruchurtu, I./SEgarra Echebarría, R. (dirs.): Introducción a la Psicopatología, Ars Medica, Barcelona, 2005, pp. 76 y ss.; PORTERo LAZCANO, G.: «La voluntad y la actividad volitiva», en Eguíluz URUCHURTU, I./SEGARRA EChebARríA, R. (dirs.): Introducción a la Psicopatología, Ars Medica, Barcelona, 2005, pp. 489 y ss.; SÁNCHEZ GÓMEZ, P. et al.: «Trastornos del contenido del pensamiento», en EGUíLUZ URUCHURTU, I./SEgARRA Echebarría, R. (dirs.): Introducción a la Psicopatología, Ars Medica, Barcelona, 2005, pp. 108 y ss.; SEgARRA ECHEBARRÍA, R. et al.: «Psicopatología de la afectividad», en Eguíluz URUChurtu, I./SEgarRa Echebarría, R. (dirs.): Introducción a la Psicopatología, Ars Medica, Barcelona, 2005, pp. 186 y ss. 


\section{a) La afectividad}

La afectividad o vida afectiva es el conjunto de sentimientos, emociones, deseos, pasiones y estados de ánimo (o humor) que impregnan los actos humanos, que les dan vida y color, que inciden en nuestra forma de pensar, de comportarnos, de relacionarnos con los demás, de disfrutar, de sufrir, de amar, de odiar, de respetar, de sentir como agradable o desagradable una experiencia, etc ${ }^{23}$.

b) La atención

La atención puede definirse como una actividad direccional sobre la que se sustentan los procesos cognitivos más complejos (conciencia, percepción, memoria,...), lo que implica que una perturbación de la primera tendrá como consecuencia alteraciones en los segundos. La atención, a su vez, suele estar modulada por los procesos emocionales y afectivos por lo que si estos últimos están alterados, también podrá verse afectada ${ }^{24}$.

\section{c) La conciencia}

La conciencia es la función psíquica mediante la cual la persona está despierta, lúcida, vigilante, alerta, se da cuenta de las cosas que ocurren a su alrededor y las integra; asimismo, permite analizar, guardar y almacenar datos y vivencias que luego podrán ser recordados. Algunos autores la definen como la «capacidad de percibir y conocer», la «capacidad de comprender y utilizar esta información de manera eficaz» ${ }^{25} \mathrm{y}$, por su complejidad, está vinculada con prácticamente todas las demás funciones psíquicas, aunque, de manera especial, con la atención y la orientación ${ }^{26}$.

d) La inteligencia

CARrasco Gómez/Maza Martín definen la inteligencia como una función compleja gracias a la cual somos capaces de conocer e identificar cosas y personas, percibir estructuras y símbolos, anticipar las consecuencias de

${ }^{23}$ Carrasco Gómez, J. J./Maza Martín, J. M.: Tratado..., ob. cit., p. 116; García García, J.: Drogodependencias y justicia penal, ob. cit., p. 185; SEGARRA ECHEBARRÍA, R. et al.: «Psicopatología de la afectividad», ob. cit., p. 167.

${ }^{24}$ Cabrera Forneiro, J./Fuertes Rocañín, J. C: Psiquiatría y Derecho:..., ob. cit., p. 135; Carrasco Gómez, J. J./Maza Martín, J. M.: Tratado..., ob. cit., p. 100; García BlÁzQuez, M.: Análisis médico-legal de la imputabilidad...., ob. cit., pp. 48 y ss.; OJEDA DEL Pozo, N. et al. : «Psicopatología de la atención», ob. cit., pp. 67 y 69.

${ }^{25}$ Marcó Ribé, J./Martí Tusquets, J. L.: Psiquiatría Forense, ob. cit., p. 83. Pueden verse más definiciones en MuÑoz Domínguez, P. et al.: "Psicopatología de la conciencia», ob. cit., pp. 13 y 14.

${ }^{26}$ Carrasco Gómez, J. J./Maza Martín, J. M.: Tratado..., ob. cit., p. 97; Marcó Ribé, J./Martí Tusquets, J. L.: Psiquiatría Forense, ob. cit., p. 87; MuÑoz Domínguez, P. et al. : «Psicopatología de la conciencia», ob. cit., pp. 13 y 17. 
una acción, recordar experiencias, organizar nuestra vida, relacionarnos con los demás, adaptarnos a situaciones nuevas, y todo ello de tal manera que sea considerado por el entorno como adecuado. La complejidad de esta función involucra a otras como la atención, la percepción, la memoria y el pensamiento $^{27}$.

Es frecuente entre los no expertos en esta materia, pretender reducir la inteligencia al clásico cociente intelectual (CI) y concluir que los sujetos que no alcanzan una cifra concreta sufren algún trastorno de dicha función, de mayor intensidad cuanto más bajo sea dicho cociente. Esta simplificación es duramente criticada por los profesionales puesto que no se corresponde con el significado y contenido de una función tan compleja como es la inteligencia ${ }^{28}$.

\section{e) La memoria}

Esta función psíquica no consiste únicamente en la capacidad de almacenar experiencias personales en el cerebro; la memoria permite actualizar vivencias anteriores, recordarlas, hacerlas llegar y presentarlas de nuevo en la conciencia, así como grabar y fijar vivencias nuevas. Se trata de un proceso, un fenómeno complejo, que presupone una capacidad atencional por parte del sujeto, posteriormente es necesaria una fase de adquisición de la información a través de las vías sensoriales; el siguiente paso es la codificación de la información y la fase final, la recuperación o acceso a la información almacenada para hacerla consciente y, en su caso, utilizarla.

27 Carrasco Gómez, J. J./Maza Martín, J. M.: Tratado..., ob. cit., pp. 129. Otras definiciones similares pueden verse en BALSA VidAL, H./FERnÁNDEZ MODAMIO, M.: «Inteligencia», en Eguíluz URuchurtu, I./SEgarRa Echebarría, R. (dirs.): Introducción a la Psicopatología, Ars Medica, Barcelona, 2005, pp. 257 y 280; CABrera ForneIRo, J./ Fuertes Rocañín, J. C: Psiquiatría y Derecho: ..., ob. cit., p. 119; Gisbert Grifo, M. S. et al.: Glosario de Psiquiatría Forense..., ob. cit., p. 121; MARCó Ribé, J./MARTí TusQUETS, J. L.: Psiquiatría Forense, ob. cit., p. 102.

${ }^{28}$ Dentro de esta función psíquica se distingue un factor general o global de inteligencia (factor G) y las inteligencias «específicas» o «sectoriales» como la inteligencia matemática, técnica, científica, literaria, analítica, creativa, manual, abstracta, memorística, verbal, numérica, lógica, etc. El valor del cociente intelectual por sí solo es insuficiente para valorar esta función psíquica, siendo preciso tener en cuenta, además, el estudio global de la personalidad, la curva y desarrollo biográfico, adaptación e integración sociales, capacidad de autonomía, etc. Un trastorno de la inteligencia no es sólo un cociente intelectual por debajo de unas cifras, es un déficit de la cognición, del conocimiento, de la comprensión, de la capacidad de juicio crítico, del juicio razonador y lógico, un déficit para asociar experiencias, para formar o adaptarse a situaciones nuevas, para resolver problemas, para crear. BALSA VidAL, H./FERNÁNDEZ MODAMIO, M.: «Inteligencia», ob. cit., p. 257; CARrasco Gómez, J. J/MAZA MARTín, J. M.: Tratado..., ob. cit., p. 129; GARCía BlázQuez, M.: Análisis médico-legal de la imputabilidad..., ob. cit., pp. 59 y 60; Gisbert Grifo, M.S. et al.: Glosario de Psiquiatría Forense..., ob. cit., p. 121. 
Algunos autores distinguen varios tipos de memoria como la verbal, visual, espacial, emocional, memoria de trabajo, memoria a corto plazo o la memoria a largo plazo y señalan que esta función psíquica está estrechamente vinculada con otras como el nivel de conciencia, el estado afectivo o la atención ${ }^{29}$.

\section{f) El pensamiento}

El pensamiento permite la formación de conceptos, la resolución de problemas, la creación de ideas y juicios, así como relacionar ideas, razonar, integrar y organizar las sensaciones, percepciones, recuerdos y experiencias. A pesar de que el pensamiento implica la participación de prácticamente todas las funciones psíquicas, no se reduce a estas, puesto que se trata de un proceso mental de alto nivel que, si bien se asienta en procesos básicos, incluye elementos adicionales, como estrategias y reglas ${ }^{30}$.

\section{g) La percepción}

La percepción ${ }^{31}$ no se reduce a una simple recogida sensorial de información y a su posterior acumulación, puesto que, además de esas fases, debe existir un posterior reconocimiento y elaboración de las sensaciones, proceso este en el que interviene el conjunto de funciones mentales. Las personas no somos meros receptores de información, sino que asumimos una participación activa al seleccionar, clasificar y configurar la información objetiva que recibimos; no se trata de efectuar una lectura pasiva del mundo circundante, sino de construirlo.

Por lo tanto, la percepción no está ligada exclusivamente a los sentidos, sino que también influyen otras funciones psíquicas como la memoria, el estado afectivo o el estado de ánimo, pero, además de estas influencias que podemos llamar personales, también hay que tener presentes las influencias socioculturales (educación, contexto cultural, religión,...) que pueden modificar este proceso $^{32}$.

${ }^{29}$ Cabrera Forneiro, J./Fuertes Rocañín, J. C: Psiquiatría y Derecho:..., ob. cit., p. 127; Carrasco Gómez, J. J./MAza Martín, J. M.: Tratado..., ob. cit., p. 101; Eguíluz URUChURTU, I. et al.: «Psicopatología de la memoria», ob. cit., pp. 45 y ss.; MARCó RIBÉ, J./Martí Tusquets, J. L.: Psiquiatría Forense, ob. cit., p. 100.

${ }^{30}$ Cabrera Forneiro, J./Fuertes Rocañín, J. C: Psiquiatría y Derecho:..., ob. cit., p. 123; Carrasco Gómez, J. J./MAza Martín, J. M.: Tratado..., ob. cit., p. 105; GisBerT Grifo, M. S. et al. Glosario de Psiquiatría Forense ..., ob. cit., p. 157; HigUeras ARANDA, A. et al.: "Trastornos formales... », ob. cit., p. 141; MARCó RIBÉ, J./MARTí TUSQUETS, J. L.: Psiquiatría Forense, ob. cit., p. 92; SÁnCHEz Gómez, P. et al. : «Trastornos del contenido del pensamiento», ob. cit., pp. 105 y 106.

${ }^{31}$ Marcó Ribé, J../Martí Tusquets, J. L.: Psiquiatría Forense, ob. cit., p. 97, consideran más preciso decir «sensopercepción».

32 Cabrera Forneiro, J./Fuertes Rocañín, J. C: Psiquiatría y Derecho:..., ob. cit., p. 136; Carrasco Gómez, J. J./Maza Martín, J. M.: Tratado..., ob. cit., p. 113; GuAdILLA FERnÁNDEZ, M. L. et al: «Psicopatología de la percepción», ob. cit., pp. 83 y ss.. 


\section{h) La voluntad}

Por último, la voluntad se puede definir como la capacidad de «elegir y decidir entre caminos distintos y de actuar según la elección tomada», la capacidad de reflexionar o decidir, de elegir, de optar, de admitir o rechazar, en definitiva, de hacer posible que una idea o un deseo, se transforme en un acto voluntario ${ }^{33}$.

En el siguiente apartado, dedicado al llamado "proceso volitivo» se volverá a hacer referencia a esta función psíquica con el objetivo de matizar los distintos significados que suele darse a la misma.

\subsubsection{El proceso volitivo}

Partiendo del contenido de la voluntad visto en las líneas anteriores, señalan algunos autores que se denomina «acto volitivo o voluntario» a aquel que surge como reacción a una decisión consciente, reflexiva y con sentido; la expresión del acto voluntario, afirman, es la expresión de la libertad ${ }^{34}$.

Este acto volitivo o voluntario es la culminación del llamado «proceso volitivo», proceso por medio del cual percibimos, deliberamos, decidimos y, finalmente, llevamos a cabo lo decidido. En este proceso, por tanto, se suceden una serie de fases que, de manera muy gráfica, representa PorTERo LazCANO con el siguiente esquema ${ }^{35}$ :

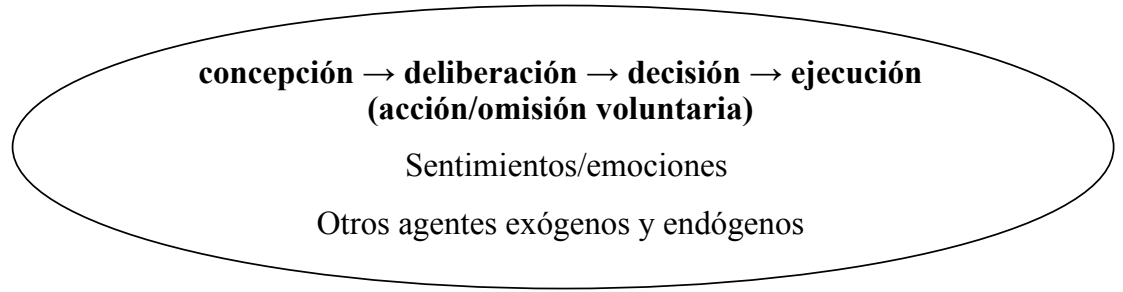

${ }^{33}$ Carrasco Gómez, J. J./Maza Martín, J. M.: Tratado..., ob. cit., pp. 120 y 121; Gisbert Grifo, M. S. et al.: Glosario de Psiquiatría Forense..., ob. cit., p. 200; Oros Muruzabal, M.: «La voluntad», ob. cit., p. 109; Portero LAZCANO, G.: «La voluntad y la actividad volitiva», ob. cit., p. 474.

${ }^{34}$ Carrasco Gómez, J. J./Maza Martín, J. M.: Tratado..., ob. cit., pp. 120 y 121; Gisbert Grifo, M. S. et al.: Glosario de Psiquiatría Forense..., ob. cit., p. 200; Oros MuruZabal, M.: «La voluntad», ob. cit., p. 109.

35 Portero Lazcano, G.: «La voluntad y la actividad volitiva», ob. cit., p. 491. Hacen una exposición similar: Cabrera Forneiro, J./Fuertes RocañIn, J. C: Psiquiatría y Derecho:..., ob. cit., p. 130; CARRASco Gómez, J. J./MAza Martín, J. M.: Tratado..., ob. cit., p. 121; Esbec Rodríguez, E./Delgado Bueno, S.: «Imputabilidad: concepto y perspectivas. La imputabilidad de los trastornos mentales», en Delgado Bueno, S. (dir.): Psiquiatría Legal y Forense, Vol. I, Colex, Madrid, 1994, p. 330; Gisbert Grifo, M. S. et al.: Glosario de Psiquiatría Forense..., ob. cit., p. 200; Oros Muruzabal, M.: «La voluntad», ob. cit., pp. 110 y ss. 
En estas fases intervienen, como no podía ser de otra manera, las funciones psíquicas mencionadas en el apartado anterior, de modo que, para que dichas fases transcurran en condiciones de normalidad y pueda decirse que el acto que resulta de ellas es un acto libre, estas funciones no deben estar alteradas ${ }^{36}$.

Debe reparar el lector en que, tal y como refleja el gráfico, los sentimientos y las emociones, es decir, la afectividad está presente en todo el proceso $\mathrm{y}$ tienen un papel facilitador o perturbador del mismo. Asimismo, se pone de relieve la existencia de circunstancias y agentes exógenos y endógenos que también afectan y condicionan dicho proceso ${ }^{37}$.

En el apartado anterior se ha señalado que la voluntad se puede definir como la capacidad de «elegir y decidir entre caminos distintos y de actuar según la elección tomada». Así definida, parece difícil diferenciar esta función psíquica del proceso volitivo, tal y como se acaba de configurar.

La dificultad que se plantea al referirse a la «voluntad» es que, la mayoría de las veces, se utiliza como sinónimo de «proceso volitivo», integrando, por tanto, las demás funciones psíquicas, de manera que la alteración de cualquiera de ellas provocará, indirectamente, la de la voluntad. Pero el vocablo «voluntad» también puede utilizarse para referirse a una función psíquica diferente y separada de las demás, identificándola con el control de los impulsos y la capacidad de inhibición, es decir, con la última fase del proceso volitivo, la ejecución.

\subsection{Las «condiciones» objeto de análisis en la imputabilidad}

Al comienzo de este artículo se indicó que, en una primera aproximación, la imputabilidad puede definirse como «aquella categoría dogmática mediante la cual se establecen las condiciones que debe tener un sujeto para que le sea atribuible penalmente el hecho antijurídico que ha realizado». A esta

${ }^{36}$ Para profundizar en el análisis de estas fases pueden consultarse, entre otras, las siguientes referencias bibliográficas: CABRERA ForneIro, J./FuERTES RocAÑín, J. C: Psiquiatría y Derecho:..., ob. cit., p. 130; CARRASco Gómez, J. J./MAZA MARTín, J. M.: Tratado..., ob. cit., p. 121; EsBec RodríGuez, E./DElgado Bueno, S.: «Imputabilidad: concepto y perspectivas...», ob. cit., p. 330; GARCÍA BLÁZQUEZ, M.: Análisis médico-legal de la imputabilidad..., ob. cit., 69 y ss.; GISBERT GRIFO, M. S. et al.: Glosario de Psiquiatría Forense..., ob. cit., p. 200; LABRADOR ENCINAS, F. J.: «El control de las conductas humanas. Por qué funcionan las conductas», en LABRADOR ENCINAS, F. J. (dir.): Aportaciones de la psicología al ámbito jurídico, Cuadernos de Derecho Judicial, n. 19, CGPJ, Madrid, 1994, pp. 28 y ss.; Oros MuruzABAL, M.: «La voluntad», ob. cit., pp. 109 y ss.; Portero LAzCANO, G.: «La voluntad y la actividad volitiva», ob. cit., p. 473 y ss.

37 García BlázQuez, M.: Análisis médico-legal de la imputabilidad..., ob. cit., pp. 69 y ss.; Oros Muruzabal, M.: «La voluntad», ob. cit., p. 109; Portero Lazcano, G.: «La voluntad y la actividad volitiva», ob. cit., pp. 475 y 491. 
definición inicial hemos añadido que dicha atribución se fundamenta en que el sujeto pudo actuar de modo distinto a como lo hizo, es decir, era libre (relativamente) para actuar conforme a derecho, pero libremente, voluntariamente decidió vulnerar y vulneró una norma penal.

Como ya se ha señalado, la libertad que fundamenta la imputabilidad es una libertad limitada (en mayor o menor medida, dependiendo de cada persona y circunstancias concretas), por múltiples factores endógenos y exógenos que concurren en el momento de tomar una decisión o llevar a cabo una conducta, como pueden ser la herencia genética, el entorno, la edad, experiencias previas, etc. ${ }^{38}$ Es decir, cuando afirmamos que un sujeto imputable ha actuado de manera libre, estamos diciendo que la decisión no es exclusivamente el resultado de leyes causales, sino que, en última instancia, es fruto de su voluntad. Pero, no podemos olvidar que también estamos afirmando que la libertad es limitada y, por tanto, que el sujeto ha estado condicionado por factores internos y externos y estos, en su caso, han podido influir en la decisión de llevar a cabo un hecho ilícito y en su posterior ejecución ${ }^{39}$. Por el contrario, si el sujeto es declarado inimputable, lo que estamos manifestando es que su decisión y/o actuación no ha sido el resultado de una voluntad libre, sino de la concurrencia de uno o varios factores que han eliminado su capacidad de autodeterminación.

En ambos casos, tanto en el supuesto de los imputables como de los inimputables se afirma la existencia de factores que condicionan la libertad de decisión y actuación. Entonces, ¿por qué unos son tan relevantes como para eliminar la imputabilidad y otros, a pesar de estar presentes, no afectan a este elemento del delito? Para responder a esta pregunta es necesario establecer un criterio que permita determinar qué factores, requisitos y condiciones hay que analizar en la imputabilidad y cuáles se considera que no afectan a la misma, a pesar de restar libertad al acto volitivo.

Como recordará el lector, en páginas precedentes se ha hecho referencia al proceso volitivo, proceso que culmina con un acto libre o voluntario, y en el cual se suceden distintas fases en las que intervienen las funciones psíquicas ya conocidas así como otros factores endógenos y exógenos.

${ }^{38}$ LÓPEZ BarJa de Quiroga, J.: «Aproximación a la culpabilidad.... », ob. cit., p. 55; García garcía, J.: Drogodependencias y justicia penal, ob. cit., p. 162; Joshi JUBert, U.: Anomalía y alteración psíquica ..., ob. cit., pp. 62 y 95; MANTOVANI, F.: «Libertad,... », ob. cit., p. 1139; SuÁrez-Mira Rodríguez, C. (coord.): Manual de Derecho Penal. Tomo I. Parte General, ob. cit., p. 176; Urruela Mora, A.: Imputabilidad penal..., ob. cit., p. 71.

39 Vencer dichos condicionantes y adoptar una decisión conforme al ordenamiento jurídico puede ser más o menos difícil dependiendo del caso concreto. CASTELLÓ NiCÁs, N.: «Exención y atenuación...», ob. cit., p. 306; LA MISMA: «Artículo 20.1», en COBO DEL Rosal, M. (dir.): Comentarios al Código Penal, Tomo II, EDERSA, 1999, p. 122; LA MISMA: La imputabilidad penal del drogodependiente, Comares, Granada, 1997, p. 67. 
Pues bien, la libertad que interesa en el análisis de la imputabilidad se refiere a la libertad (limitada) de decisión (o elección) y de ejecución, si bien, tomando como referencia el proceso volitivo, parece evidente que, para que estas fases sean libres, las anteriores, es decir, la fase de concepción y deliberación, también deben serlo. Por ese motivo el objeto de análisis en la imputabilidad debe ser la libertad del proceso volitivo concreto que ha tenido como resultado el hecho ilícito que se pretende imputar a un individuo, el proceso en sí mismo considerado, su estructura, el desarrollo adecuado de sus fases ${ }^{40}$.

Una vez limitado el objeto del análisis de la imputabilidad a la estructura del proceso volitivo, hay que concretar cuáles son los componentes de dicha estructura, es decir, cómo se determina si la misma está alterada o no, cuáles son los parámetros a valorar.

La tesis que se sostiene en este trabajo es que los requisitos y condiciones que hay que analizar en la imputabilidad son las funciones psíquicas que intervienen en el proceso volitivo y que, como sabemos son, la afectividad, la atención, la conciencia, la inteligencia, la memoria, el pensamiento, la percepción y la voluntad. Todas ellas intervienen en dicho proceso, en una o varias fases, por lo que la alteración de cualquiera de ellas puede afectar a la estructura del mismo y, consecuentemente, a la imputabilidad ${ }^{41}$. Por el contrario, si el funcionamiento de las capacidades o funciones psíquicas intervinientes en el proceso volitivo es correcto, la estructura de dicho proceso no habrá sufrido alteraciones y, por lo tanto, podrá afirmarse que las fases del mismo se han sucedido de forma adecuada dando lugar a una decisión y a un acto voluntario y libre.

Si las funciones psíquicas están en perfectas condiciones, el individuo ha podido percibir adecuadamente su entorno y los estímulos, tanto endógenos como exógenos, existentes. Posteriormente, ante la duda de si llevar a cabo o no el hecho delictivo, ha podido deliberar en libertad, es decir, valorando de forma adecuada el significado del acto pretendido, los pros y contras de su decisión, las posibilidades de éxito, de fracaso, etc. En un momento ulterior este sujeto ha sido capaz de decidir en libertad sobre el acto a realizar, es decir, aunque hayan existido razones o motivos que le hayan hecho inclinarse más por una u otra opción, en lo que aquí interesa, por llevar a cabo o no el hecho ilícito, ha podido no realizarlo. Y, finalmente, si la decisión era no realizar el hecho ilícito le ha sido posible inhibir la conducta ilícita, aunque, en última instancia, no lo haya hecho.

${ }^{40}$ En sentido parecido, DíEz RipollÉs, J. L.: «Aspectos generales de la imputabilidad», ob. cit., pp. 23 y ss.; MARTÍNEZ GARAY, L.: La imputabilidad penal:..., ob. cit., pp. 249 y ss.

${ }_{41}$ En el mismo sentido Martínez GAray, L.: La imputabilidad penal: ..., ob. cit., pp. 350 y ss 
Solo si estas facultades psíquicas funcionan adecuadamente podremos concluir que la estructura del proceso volitivo que ha tenido como resultado el hecho ilícito objeto de enjuiciamiento no se ha visto alterada y, por lo tanto, el proceso volitivo así como dicho hecho ilícito, podrán calificarse de voluntarios o libres. Consecuentemente, el hecho ilícito puede serle imputado a su autor puesto que ha podido decidir libremente no llevarlo a cabo e inhibir su comisión. Lo importante no es lo que finalmente el sujeto haya decidido o realizado (el hecho ilícito), lo verdaderamente relevante es que las fases del proceso volitivo se han dado en condiciones de normalidad, sin alteraciones en las funciones psíquicas intervinientes en las mismas.

Por el contrario, si hay alguna alteración en las mencionadas funciones, la decisión no será «libre», puesto que el sujeto no ha podido percibir adecuadamente la realidad o llevar a cabo una deliberación libre, o bien no ha podido decidir en sentido contrario a la realización del hecho ilícito o inhibir la conducta que se ha decidido no realizar.

En conclusión, considero que los factores, requisitos o condiciones relevantes para el juicio de imputabilidad hacen referencia al estado de las funciones psíquicas que intervienen en el proceso volitivo en sí mismo considerado, en su estructura, es decir, a la presencia o no de alteraciones en la afectividad, la atención, la conciencia, la inteligencia, la memoria, el pensamiento, la percepción y la voluntad.

\subsection{Especial referencia a los factores socioculturales}

No suele ponerse en duda que la imputabilidad es una categoría del delito en la cual el objeto de análisis es la situación específica en la que se encuentra el sujeto concreto que ha llevado a cabo un hecho ilícito determinado; se trata de un juicio individualizado sobre dicha situación ${ }^{42}$. Podría parecer que la tesis aquí propuesta no respeta esta necesidad de individualización pues, como he afirmado, se reconoce que hay factores endógenos y exógenos que influyen en el individuo distintos de las funciones psíquicas que intervienen en el proceso volitivo, pero que no van a ser tenidos en cuenta en el análisis de esta categoría del delito. Es decir, habrá supuestos en los cuáles se acepte que el proceso volitivo que ha tenido como resultado la realización de un hecho ilícito ha estado condicionado por la presencia de circunstancias ajenas al estado de las funciones psíquicas del sujeto (por ejemplo, una situación económica precaria, carencias en el proceso educativo,...) y, sin embargo, ello no tenga ninguna repercusión en la imputabilidad, declarando al sujeto plenamente imputable, lo que parece contradecir la configuración de la imputabilidad como un juicio individualizado.

${ }^{42}$ Por todos, Mir Puig, S.: Derecho Penal. Parte General, ob. cit., pp. 539 y ss. 
Sin perjuicio de que algunos de esos factores pueden ser tenidos en cuenta en otros elementos del delito, acepto que esta es una de las críticas que puede hacerse a la solución aquí propuesta.

En este sentido, un sector doctrinal considera que el juicio de imputabilidad no puede ignorar la existencia de factores socioculturales que condicionan nuestro comportamiento y, en lo que aquí interesa, la libertad del proceso volitivo, de modo que estos factores deben ser tenidos en cuenta, junto al estado de las funciones psíquicas del individuo, en el análisis de la imputabilidad si queremos que sea un juicio realmente individualizador que contemple la situación concreta en la que se encontraba el sujeto en el momento de llevar a cabo el hecho ilícito ${ }^{43}$.

Entre estos factores se menciona la cultura a la que pertenece el sujeto, su educación, formación, profesión, situación económica, situación familiar, también aspectos como la emigración, el desconocimiento del idioma, la falta de integración social, el abandono juvenil, la inadaptación, la marginación, alteraciones en el proceso de socialización e incluso algunos autores consideran relevante la situación económica y el régimen político del país en el que está el individuo ${ }^{44}$.

Estoy de acuerdo con la afirmación de que en el proceso volitivo intervienen múltiples factores endógenos y exógenos, entre ellos los socioculturales, que van a condicionar la libertad de dicho proceso pero, como ya he señalado, considero que no tienen que ser objeto de análisis en la imputabilidad, puesto que en este elemento del delito solo nos interesa el estado en el que se encuentran las funciones psíquicas que intervienen en el proceso volitivo. Si los factores socioculturales tienen reflejo en una alteración de dichas funciones, podrán influir en la imputabilidad de manera indirecta ${ }^{45}$; de otro modo, solo repercutirán en la responsabilidad penal del sujeto si pueden dar lugar a

${ }^{43}$ DíEz Ripollés, J. L.: Los elementos subjetivos del delito. Bases metodológicas, $2^{\mathrm{a}}$ edición, B de F, Buenos Aires, 2007, p. 294; GARcía BlázQuez, M.: Análisis médico-legal de la imputabilidad..., ob. cit., pp. 42 y ss.; Muñoz Conde, F./García Arán, M.: Derecho Penal. Parte General, ob. cit., p. 362; NAQuira Riveros, J.: «Imputabilidad, conciencia de lo injusto y contexto situacional normal: de su objeto, contenido y relación», $C P C$, n. 55, 1995, p. 144; SuÁrez-Mira RodríGuez, C.: La imputabilidad del consumidor de drogas, Tirant lo Blanch, Valencia, 2000, pp. 79 y 97.

${ }^{44}$ García BlázQuez, M.: Análisis médico-legal de la imputabilidad..., ob. cit., pp. 42 y 43; MARTínez ARrietA, A.: «Tratamiento penal de las circunstancias que reflejan una menor culpabilidad. Especial referencia a la alteración de la percepción», en MARTíNEZ Arrieta, A. (dir.): Psiquiatría Criminal y comportamientos violentos, Cuadernos de Derecho Judicial, n. 8, CGPJ, Madrid, 2005, p. 321; MuÑoz conde, F./García ArÁN, M.: Derecho Penal. Parte General, ob. cit., p. 369; NAQUIRA Riveros, J.: «Imputabilidad, conciencia de lo injusto...», ob. cit., p. 142; PAdilla AlBA, H. R.: «El fundamento de la capacidad de culpabilidad...», ob. cit., p. 956; EL MISMO: Exención y atenuación ..., ob. cit., p. 104.

${ }^{45}$ En el mismo sentido, Martínez Garay, L.: La imputabilidad penal:..., ob. cit., p. 353. 
la aplicación de alguna exención o disminución de la responsabilidad penal cuyo fundamento sea la afectación a otro elemento del delito ${ }^{46}$, elemento que, generalmente, se ha identificado con la exigibilidad de conducta distinta ${ }^{47}$.

La contemplación de estos factores, como señala MARTínEZ GARAY, obedece al «comprensible designio de realizar un juicio de culpabilidad lo más individualizado posible ${ }^{48}$, pero da paso a la posibilidad de que se generen situaciones de desigualdad e inseguridad ${ }^{49}$ en la determinación de un elemento, la imputabilidad, ya de por sí difícil de estimar ${ }^{50}$, puesto que sería prácticamente imposible hacer un catálogo cerrado de los factores socioculturales que deben ser analizados. A esta dificultad hay que añadir la que supondría determinar hasta qué punto las carencias que el sujeto tiene en el ámbito sociocultural son responsabilidad de la sociedad, del Estado o han sido, en todo o en parte, responsabilidad suya, consecuencia de decisiones y opciones libres que ha ido tomando a lo largo de su vida.

Una decisión concreta depende de tantos factores que «cae fuera de las posibilidades humanas abarcarlos, averiguar cómo han actuado en el caso concreto» ${ }^{51} \mathrm{y}$, de hecho habrá factores y motivos que no consten en absoluto porque están ocultos «incluso para el propio sujeto» ${ }^{52}$. Es decir, una total individualización resulta, en la práctica, poco menos que imposible.

La propuesta aquí defendida, si bien no garantiza una total individualización de la situación en la que se encontraba el sujeto, sí garantiza la seguridad

${ }^{46}$ De la misma opinión Martínez Garay, L.: La imputabilidad penal:..., ob. cit., pp. 349 y ss. OBREgón GARCÍA propone considerar a estos factores elementos anteriores, posteriores o simultáneos al delito, pero sin formar parte de él, si bien, en tanto se reflejan e influyen en la infracción, contribuyen a graduar la responsabilidad, lo que, en su opinión, podría dar lugar a la aplicación de una atenuante. En La atenuación de la pena. Sentido y regulación legal de la llamada atenuación extraordinaria, con especial referencia a las eximentes incompletas y a las atenuantes muy calificadas, Universidad Pontificia de Comillas de Madrid, Madrid, Dykinson, 1998, p. 214.

${ }^{47}$ Aunque quizás sea este el tratamiento más adecuado, sería necesario un análisis detenido de este elemento del delito (exigibilidad de conducta distinta), análisis que excede los objetivos del presente artículo.

${ }^{48}$ Reconoce esta autora que es «una meta a la que tender, pero que por la propia esencia del concepto de culpabilidad jurídica nunca puede ser alcanzada completamente», luego, algunos factores necesariamente tendrán que ser dejados siempre fuera de consideración. MARTínez GARAY, L.: La imputabilidad penal:..., ob. cit., pp. 353 y 354.

${ }^{49}$ Cabrera Forneiro, J./Fuertes Rocañín, J. C.: Psiquiatría y Derecho...., ob. cit., p. 155.

${ }^{50}$ Martínez Garay, L.: La imputabilidad penal:..., ob. cit., p. 350.

${ }^{51}$ Gimbernat Ordeig, E.: «¿Tiene un futuro la dogmática jurídicopenal?», en GimBernat Ordeig, E.: Estudios de Derecho Penal, Tecnos, Madrid, 1990, p. 144. También Martínez GARAY, L.: La imputabilidad penal:..., ob. cit., p. 378, considera que una absoluta individualización es imposible.

52 Martínez GAray, L.: La imputabilidad penal:..., ob. cit., p. 382. 
jurídica, puesto que ofrece un catálogo cerrado y bien definido de los aspectos a analizar siempre y en todo caso en la imputabilidad. Ahora bien, lo que sí será necesario para que este criterio cumpla sus propósitos es la realización de una pericia completa y exhaustiva sobre las funciones psíquicas del sujeto en relación con el proceso volitivo concreto de que se trate, no bastando con un análisis general y superficial de las mismas.

Ello no obsta para que el informe que, en su caso, elabore el perito sí pueda contener referencias a otro tipo de factores exógenos y endógenos (entre ellos los socioculturales) que, de un modo u otro, hayan podido influir en el proceso volitivo que ha tenido como resultado el hecho ilícito objeto de enjuiciamiento. Estos podrán ser tenidos en cuenta y valorados por el órgano judicial competente para aplicar algún tipo de exención o circunstancia modificativa de la responsabilidad penal cuyo fundamento no sea la imputabilidad, para comprender mejor las circunstancias que han rodeado la comisión del hecho ilícito o para ayudarle a decidir cuál es la consecuencia jurídica más adecuada ${ }^{53}$.

\section{LA IMPUTABILIDAD EN EL CÓDIGO PENAL DE 1995. COMPATIBILIDAD CON EL CONCEPTO DE IMPUTABILIDAD PROPUESTO}

El Código Penal vigente dispone en los artículos 20.1 y 20.2 que está exento de responsabilidad criminal el que, por sufrir una alteración o anomalía psíquica, intoxicación o síndrome de abstinencia, no pueda «comprender la ilicitud del hecho» o «actuar conforme a esa comprensión». La doctrina mayoritaria considera que de esta expresión, a sensu contrario, debe deducirse el contenido que el legislador ha querido dar a la imputabilidad en la legislación penal vigente; de hecho, numerosos autores definen la imputabilidad como la «capacidad para comprender la ilicitud del hecho y actuar conforme a esa comprensión $»^{54}$.

Si se acepta que el legislador define en estos preceptos cómo debe entenderse la imputabilidad en nuestro ordenamiento, la pregunta que debemos hacernos es si el concepto de imputabilidad defendido en el apartado anterior es compatible con el que se desprende del texto legal. Para responder a esta

${ }^{53}$ De la misma opinión Martínez GARAY, L.: La imputabilidad penal: ..., ob. cit., pp. 350 y ss.

${ }_{54}$ Por todos, Higuera GuIMERÁ, J. F.: «La prueba pericial psiquiátrica en los procedimientos judiciales penales y la medicina forense en España: una respetuosa llamada «urgente» de atención», en CARBOnell MATEU, J. C. et. al. (coords.): Estudios penales en Homenaje al Profesor Cobo del Rosal, Dykinson, Madrid, 2005, p. 504; PADILla AlBA, H. R: «Art. 20.2», en Cobo del Rosal, M. (dir.), Comentarios al Código Penal, Tomo II, EDERSA, Madrid, 1999, p. 254. 
pregunta es necesario analizar detenidamente cuál es el contenido que hay que dar a la expresión transcrita y, posteriormente, compararlo con dicho concepto.

A continuación va a analizarse, en primer lugar, el significado de la expresión «capacidad para comprender la ilicitud del hecho», en segundo lugar, «capacidad para actuar conforme a esa comprensión» y, finalmente, se concluirá sobre la compatibilidad de estas expresiones y el concepto de imputabilidad propuesto.

\subsection{Capacidad para comprender la ilicitud del hecho}

Tradicionalmente, se ha considerado que la capacidad de comprensión dependía únicamente de la inteligencia del sujeto y se hacía referencia a ella con la expresión «elemento intelectivo» de la imputabilidad ${ }^{55}$. Actualmente, la opinión mayoritaria considera que no es esta la única función psíquica involucrada en el proceso de comprensión y que es más adecuado denominarlo «elemento cognitivo ${ }^{56} \mathrm{o}$ «cognoscitivo» ${ }^{57}$, añadiendo algunos autores el vocablo «-valorativo» ${ }^{58}$.

\subsubsection{Capacidad para comprender}

¿Qué significa «comprender»? Según la $22^{\mathrm{a}}$ edición del Diccionario de la RAE, comprender es «entender, alcanzar, penetrar» ${ }^{59}$. Entender se define como «conocer, penetrar» ${ }^{60}$ y conocer como «entender, advertir, saber» ${ }^{61}$.

55 Por todos, Urruela Mora, A.: Imputabilidad penal..., ob. cit., p. 178.

${ }^{56}$ CARrasco Gómez, J. J.: «Circunstancias psíquicas que modifican la imputabilidad», en AAVV: IV Congreso Andaluz de Ciencias Penales. Derecho Penal y Psiquiatría Criminal y Forense, El Puerto de Santa María, 1998, p. 158; OrTEgA-MonAsterio, L.: «La imputabilidad desde el punto de vista clínico», en OrTEGA-MONASTERIO, L. et al.: Psicopatología Jurídica y Forense, Vol. I, PPU, Barcelona, 1991, p. 185.

${ }^{57}$ Fonseca Morales, G. M.: Exención y atenuación de la responsabilidad criminal ..., ob. cit., p. 31; GARCÍA GARCÍA, J.: Drogodependencias y justicia penal, ob. cit., p. 131; Padilla Alba, H. R: «El fundamento de la capacidad de culpabilidad...», ob. cit., p. 951; SuÁrez-Mira Rodríguez, C. (coord.): Manual de Derecho Penal. Tomo I. Parte General, ob. cit., p. 250.

${ }^{58}$ Martínez Arrieta, A.: «Tratamiento penal de las circunstancias...», ob. cit., p. 321; NAquira Riveros, J.: «Imputabilidad, conciencia de lo injusto...», ob. cit., p. 144; SuÁreZ-Mira Rodríguez, C.: La imputabilidad del consumidor de drogas, ob. cit., p. 86; TORÍo LÓPEZ, Á.: «Imputabilidad general e individual en la teoría jurídica del delito», en DíEz Ripollés, J. L. et. al. (eds.): La ciencia del Derecho Penal ante el nuevo siglo. Libro Homenaje al Profesor Doctor Don José Cerezo Mir, Tecnos, Madrid, 2003, p. 1020.

$5922^{\mathrm{a}}$ edición del Diccionario de la RAE. http://lema.rae.es/drae/?val=comprender.

${ }_{60} 22^{\mathrm{a}}$ edición del Diccionario de la RAE. http://lema.rae.es/drae/?val=entender.

${ }^{61} 22^{\mathrm{a}}$ edición del Diccionario de la RAE. http://lema.rae.es/drae/?val=conocer. 
Parece pues que todos estos verbos pueden utilizarse como sinónimos y, de hecho, son numerosos los autores que al referirse a este vocablo contenido en los arts. 20.1 y 20.2 utilizan indistintamente los verbos entender, penetrar, conocer, saber, advertir, discernir, captar o aprehender ${ }^{62}$.

Algunos de los significados de estos términos que ofrece el Diccionario mencionado se limitan a enumerar sinónimos ${ }^{63}$, pero otros son más descriptivos y nos pueden ayudar en la tarea de dar contenido a este vocablo. Alcanzar, por ejemplo, se define como «llegar a percibir con la vista, el oído o el olfato» ${ }^{64}$; penetrar como «fijar en algo la atención, reparar, observar» y también «comprender el interior de alguien, o algo dificultoso» ${ }^{65}$; conocer es «averiguar por el ejercicio de las facultades intelectuales la naturaleza, cualidades y relaciones de las $\cos a s »^{66}$ y entender $\langle\text { tener idea clara de las } \operatorname{cosas}\rangle^{67}$.

Un sector doctrinal señala que, además de conocer una realidad, para declarar a un sujeto imputable, es necesario que sea capaz de valorarla, es decir, de darse cuenta de su valor social, de poder contrastar el hecho con un marco o esquema normativo para poder calificarlo de lícito, ilícito, valioso o disva$\operatorname{lioso}^{68}$. Siguiendo esta tesis, consideran algunos autores más adecuado utilizar el verbo «comprender» que «conocer», porque, afirman, el primero implica una valoración no incluida en el segundo ${ }^{69}$.

En mi opinión esta diferenciación no es necesaria pues, como acabo de señalar, se trata de términos que pueden considerarse sinónimos. Es cierto que

${ }^{62}$ Carrasco Gómez, J. J.: «Circunstancias psíquicas...», ob. cit., p. 158; Carrasco Gómez, J. J./Maza Martín, J. M.: Tratado..., ob. cit., p. 290; MAza Martín, J. M.: «Arts. 20.1. ${ }^{\circ}, .^{\circ}$ y $3 .^{\circ}{ }^{\prime}$, en Conde-Pumpido Tourón, C. (dir.)/López BarJa DE Quiroga, J. (coord.): Comentarios al Código Penal, Tomo I, Bosch, Barcelona, 2007, p. 144; OrTs Berenguer E./González Cussac, J. L.: Compendio de Derecho Penal. Parte General, ob. cit., p. 306; Serrano Butragueño, I.: «Art. 20», ob. cit.-, p. 364.

${ }^{63}$ Comprender se define como entender, alcanzar, penetrar; saber cómo conocer o tener conocimiento y alcanzar como saber, entender, comprender.

${ }_{64} 22^{\mathrm{a}}$ edición del Diccionario de la RAE. http://lema.rae.es/drae/?val=alcanzar.

$6522^{\mathrm{a}}$ edición del Diccionario de la RAE. http://lema.rae.es/drae/?val=penetrar.

${ }_{66} 22^{\mathrm{a}}$ edición del Diccionario de la RAE. http://lema.rae.es/drae/?val=conocer.

$6722^{\mathrm{a}}$ edición del Diccionario de la RAE. http://lema.rae.es/drae/?val=entender.

${ }^{68}$ Fonseca Morales, G. M.: La anomalía o alteración psíquica como eximente o atenuante de la responsabilidad criminal, Madrid, Dykinson, 2009, p. 48; MARTíNEZ ARRIETA, A.: «Tratamiento penal de las circunstancias...», ob. cit., p. 321; MAZA MARTín, J. M.: «Arts. 20.1 $.^{\circ},{ }^{\circ}{ }^{\circ}$ y $3 .^{\circ}{ }^{\circ}$, ob. cit., p. 146; NAQUIRA RIVEROS, J.: «Imputabilidad, conciencia de lo injusto...», ob. cit., p. 145; OrTs Berenguer, E./GonzÁlez CussaC, J. L.: Compendio de Derecho Penal. Parte General, ob. cit., p. 306; SuÁrez-Mira RodríGuez, C (coord.): Manual de Derecho Penal. Tomo I. Parte General, ob. cit., p. 250; EL MISMO: La imputabilidad del consumidor de drogas, ob. cit., p. 89.

${ }^{69}$ Martínez Arrieta, A.: «Tratamiento penal de las circunstancias...», ob. cit., p. 321; NAQUIRA RIVEROS, J.: «Imputabilidad, conciencia de lo injusto...», ob. cit., p. 145; TORÍo LóPEZ, A.: «Imputabilidad general e individual...», ob. cit., p. 1019. 
en los últimos años se ha extendido en la doctrina la opinión de que el término comprender implica un proceso psíquico más complejo que conocer, pero no creo que deba hacerse esta distinción. De hecho, conocer implica, como acabo de indicar, averiguar las cualidades y relaciones de las cosas y para eso es necesario valorar y contrastar. A pesar de todo y, teniendo en cuenta que el Código Penal utiliza el término comprender, puede ser adecuado utilizarlo de manera preferente, pero, insisto, sólo por este motivo, no porque describa un proceso psíquico diferenciado y más complejo que «conocer».

\subsubsection{La ilicitud del hecho}

El Código Penal exige, para declarar inimputable a un sujeto, que no pueda comprender «la ilicitud del hecho», expresión esta sobre cuyo significado existen opiniones divergentes en la doctrina.

En este trabajo se defiende que, para declarar a un sujeto imputable, este debe ser capaz de entender que el hecho se halla prohibido por el Derecho, que el acto es antijurídico, ilícito ${ }^{70}$, matizando que esta exigencia se refiere a una ilicitud general, no penal, bastando con que se pueda comprender que la conducta es contraria al ordenamiento jurídico, que está prohibida y castiga$\mathrm{da}^{71}$. No se trata, como acertadamente señala NAQUiRA RIVERos, de que el individuo sepa de forma pormenorizada si una conducta específica es injusta o no $^{72}$, sino de que el individuo pueda comprender «la norma que inspira el injusto base o rector (antijuridicidad material) soporte común a todos los delitos de un ámbito jurídico-penal determinado» ${ }^{73}$.

Antes de finalizar este apartado hay subrayar que lo que se exige en la imputabilidad no es que efectivamente el sujeto haya comprendido que el

${ }^{70}$ LEGANÉs GÓMEZ, S.: «Enfermedad mental y delito (perspectiva jurídica y criminológica)», La Ley Penal: Revista de Derecho Penal, Procesal y Penitenciario, n. 76, 2010, www.laleydigital.es, p. 16; MIR PUIG, S.: «La imputabilidad en Derecho Penal», ob. cit., p. 155 .

${ }_{71}$ Cerezo Mir, J.: Curso de Derecho Penal español. Parte General..., ob. cit., p. 52; Fonseca Morales, G. M.: Exención y atenuación de la responsabilidad criminal..., ob. cit., pp. 137 y 138; MAZA MARTín, J. M.: «Arts. 20.1. ${ }^{\circ}$, 2..$^{\circ}$ y 3. ${ }^{\circ} »$, ob. cit., p. 145.

Otras opiniones pueden verse en Fonseca Morales, G. M.: Exención y atenuación de la responsabilidad criminal..., ob. cit., p. 31; García García, J.: Drogodependencias y justicia penal, ob. cit., p. 132; SERRANo ButragueÑo, I.: «Art. 20», ob. cit., p. 364

72 Naquira Riveros, J.: «Imputabilidad, conciencia de lo injusto...», ob. cit., p. 150.

${ }^{73}$ Por ejemplo, en los delitos contra la vida y la salud, basta con que sea capaz de comprender que poner en peligro o destruir una vida o atentar contra la salud es ilícito; en los delitos contra la propiedad, que sea capaz de comprender que la apropiación de cosa ajena sin voluntad del dueño está prohibida; en los delitos contra la libertad sexual, que la satisfacción del impulso sexual sin la voluntad de la persona es contraria al ordenamiento, etc. NAQUIRA RIVEROS, J.: «Imputabilidad, conciencia de lo injusto...», ob. cit., pp. 151 y ss. 
hecho realizado está prohibido, sino que haya sido posible esta comprensión, es decir, es suficiente la capacidad de comprensión para declarar a un individuo imputable ${ }^{74}$, basta con demostrar que las facultades psíquicas necesarias para dicha comprensión no estaban alteradas, lo que nos llevan a la siguiente cuestión: ¿cuáles son las funciones psíquicas implicadas en el proceso de compresión?

\subsubsection{Funciones psíquicas que intervienen en el proceso de comprensión de la ilicitud del hecho}

Como se ha señalado, ha sido frecuente relacionar la capacidad de comprensión exclusivamente con la inteligencia; sin embargo, actualmente, se considera que es necesaria la intervención de otras funciones psíquicas adicionales para poder comprender, funciones que suelen incluirse en la expresión «capacidades cognoscitivas» $\mathrm{o}$ 《capacidades cognitivas».

«Cognoscitivo» se puede definir como «que es capaz de conocer» ${ }^{75}$ y «cognitivo» como "perteneciente o relativo al conocimiento» ${ }^{76}$. Teniendo en cuenta que, como se ha indicado, conocer y comprender puede utilizarse como sinónimos, me parece correcto utilizar estas expresiones para incluir las funciones o facultades psíquicas necesarias para poder comprender la ilicitud del hecho.

Pero, ¿cuáles son esas capacidades o facultades?, es decir, de las funciones psíquicas analizadas en las páginas precedentes, ¿cuáles intervienen en este proceso de comprensión?

Señala SuÁrez-Mira Rodríguez que el proceso de conocimiento, de comprensión es muy complejo: comienza por la percepción de un objeto proveniente del mundo sensible que el sujeto integra con otras sensaciones y percepciones precedentes para dar un significado a lo percibido, proceso en el que intervienen junto a la percepción, la atención, la conciencia y la memoria. Pero, además, para que el sujeto comprenda la ilicitud del hecho, es necesario que pueda darse cuenta del valor social del acto realizado, de si es valioso o disvalioso, permitido o no; proceso en el que intervienen la inteligencia y el pensamiento ${ }^{77}$.

${ }^{74}$ García García, J.: Drogodependencias y justicia penal, ob. cit., p. 132; NAQUIRA RIVERos, J.: «Imputabilidad, conciencia de lo injusto...», ob. cit., pp. 145 y 146; SUÁREZMira Rodríguez, C. (coord.): Manual de Derecho Penal. Tomo I. Parte General, ob. cit., p. 251; Urruela Mora, A.: Imputabilidad penal..., ob. cit., p. 165.

${ }^{75} 22^{\mathrm{a}}$ edición del Diccionario de la RAE. http://lema.rae.es/drae/?val=cognoscitivo.

$7622^{\mathrm{a}}$ edición del Diccionario de la RAE. http://lema.rae.es/drae/?val=cognitivo.

77 SuÁREZ-Mira Rodríguez, C.: La imputabilidad del consumidor de drogas, ob. cit., p. 87. En sentido similar, MARTínez ArRIETA, A.: «Tratamiento penal de las circunstancias...», ob. cit., p. 321. 
En sentido similar, señalan CARRASCo Gómez/MAZA MARTín que el conocimiento es el resultado de la integración de muy diferentes e importantes funciones psíquicas, puesto que para poder llegar a conocer es preciso tener una conciencia lúcida, estar despiertos, atentos, orientados con relación a nosotros mismos y al entorno, poder percibir a través de los sentidos todo lo que nos rodea, enviar la información al cerebro, pensar, aprender y poder elaborar aquella e interpretarla, almacenarla y disponer de ella, utilizarla en un momento determinado ${ }^{78}$.

En conclusión, se puede señalar que el proceso de conocimiento o comprensión requiere la participación de prácticamente todas las funciones psíquicas que, como se ha visto, intervienen en el proceso volitivo (atención, conciencia, inteligencia, memoria, pensamiento, percepción $)^{79}$, por lo que las perturbaciones que, en su caso, sufran las mismas, impedirán o dificultarán la comprensión de la ilicitud del hecho, lo que repercutirá en la imputabilidad del individuo que, consecuentemente, se verá anulada o disminuida.

Como seguramente ha percibido el lector, en esta enumeración falta por mencionar la afectividad y la voluntad.

En relación con la primera, hay que recordar que se trata de una función estrechamente relacionada con las demás, por lo que no hay inconveniente en considerarla incluida entre las intervinientes en el proceso de comprensión.

Por lo que respecta a la voluntad entendida en sentido estricto, es decir, no identificada con el proceso volitivo y por lo tanto integrada por el resto de funciones, sino entendida como una función psíquica diferenciada de las demás, no interviene en el proceso de comprensión de la ilicitud del hecho, por lo que su alteración no tendrá influencia en el mismo.

\subsection{Capacidad para actuar conforme a esa comprensión}

La imputabilidad, tal y como se configura en el Código Penal, no se reduce al análisis de la capacidad para comprender la ilicitud del hecho, sino que exige también que el individuo pueda actuar conforme a esa comprensión. Esta capacidad se identifica habitualmente con la voluntad o capacidad volitiva ${ }^{80}$, si bien,

${ }^{78}$ Carrasco Gómez, J. J./Maza Martín, J. M.: Tratado..., ob. cit., p. 290. En sentido similar, MAza MARTín, J. M.: «Arts. 20.1. $.^{\circ}, 2 .^{\circ}$ y 3. ${ }^{\circ} »$, ob. cit., p. 144; RIERA TÁBOAS, A. et. al.: «Prueba de las causas modificadoras de la imputabilidad», en Psicología del testimonio y prueba pericial, Cuadernos de Derecho Judicial, n. 7, CGPJ, Madrid, 2005, p. 2.

79 También mencionan estas funciones psíquicas García Blázquez, M.: Análisis médico-legal de la imputabilidad..., ob. cit., p. 88; MARTínez GARAY, L.: La imputabilidad penal:..., ob. cit., p. 361; ORTEGA-MONASTERIO, L.: «La imputabilidad desde el punto de vista clínico», ob. cit., p. 185.

${ }^{80}$ García BlázQuez, M.: Análisis médico-legal de la imputabilidad..., ob. cit., p. 88; García García, J.: Drogodependencias y justicia penal, ob. cit., p. 131; MARTíneZ 
actualmente, se utilizan en su lugar expresiones como capacidad de determinación o autodeterminación ${ }^{81}$, de autoconducción ${ }^{82}$, autocontrol ${ }^{83}$, de autogobernarse ${ }^{84}$ o de controlar los impulsos ${ }^{85}$.

En la bibliografía consultada no existe una opinión unánime sobre cuál es el contenido que hay que dar a esta capacidad. Algunos autores la identifican con la aptitud para poder elegir o decidir no llevar a cabo el hecho previamente comprendido como ilícito ${ }^{86}$, otros con la capacidad de inhibir dicho comportamiento, es decir, de llevar a cabo un hecho distinto al comprendido como ilícito ${ }^{87} \mathrm{y}$, un tercer grupo incluye la capacidad de decisión o elección así como la de inhibición, debiendo concurrir ambas para entender que el individuo podía «actuar conforme a esa comprensión» ${ }^{88}$.

Los autores mencionados en último lugar consideran que para declarar a un sujeto imputable, una vez que se ha comprobado que es capaz de comprender que el hecho que pretende realizar es ilícito, tiene que tener una «doble» capacidad. En primer lugar, tiene que ser capaz de elegir, de decidir no llevar a cabo dicho hecho, de manera que esa comprensión de la ilicitud

Arrieta, A.: «Tratamiento penal de las circunstancias...», p. 322; SUÁREZ-MirA RodríGuez, C. (coord.): Manual de Derecho Penal. Tomo I. Parte General, ob. cit., p. 251; Urruela Mora, A.: Imputabilidad penal..., ob. cit., p. 178.

${ }^{81}$ Maza Martín, J. M.: «Arts. 20.1. $.^{\circ}, 2^{\circ}$ y 3. ${ }^{\circ} »$, ob. cit., p. 135; Mir PUIG, S.: Derecho Penal. Parte General, ob. cit., pp. 569 y 570; EL MISMO: «La imputabilidad en Derecho Penal», ob. cit., p. 155; NAQUIRA RIVERos, J.: «Imputabilidad, conciencia de lo injusto...», ob. cit., p. 151; SERRANO ButragueÑo, I.: «Art. 20», ob. cit., pp. 356 y 364.

${ }^{82}$ Subijana Zunzunegui, I. J.: «El Código Penal ante la enfermedad mental...», ob. cit., p. 220.

${ }^{83}$ Fonseca Morales, G. M.: La anomalía o alteración psíquica ..., ob. cit., p. 50; Mir Puig, S.: Derecho Penal. Parte General, ob. cit., pp. 569 y 570; EL MISMO: «La imputabilidad en Derecho Penal», ob. cit., p. 155; SERrano ButragueÑo, I.: «Art. 20», ob. cit., p. 364.

${ }^{84}$ Fonseca Morales, G. M.: La anomalía o alteración psíquica..., ob. cit., p. 50; Serrano ButragueÑo, I.: «Art. 20», ob. cit., pp. 356 y 364.

${ }^{85}$ Cuello Contreras, J./Mapelli Caffarena, B.: Curso de Derecho Penal. Parte General, ob. cit., p. 110.

${ }^{86}$ García García, J.: Drogodependencias y justicia penal, ob. cit., p. 135.

${ }^{87}$ Martínez Arrieta, A.: "Tratamiento penal de las circunstancias...», ob. cit., p. 323. También LuZÓN PEÑa considera que se refiere a los mecanismos inhibitorios o de control. En «Observaciones sobre culpabilidad y pena en el Código Penal español de 1995», en CEREzo Mir, J. et. al. (eds.): El nuevo Código Penal: presupuestos y fundamentos. Libro Homenaje al Profesor Doctor Don Ángel Torio López, Comares, Granada, 1999, p. 164.

${ }^{88}$ Maza Martín, J. M.: «Arts. 20.1. ${ }^{\circ}, 2^{\circ}{ }^{\circ}$ y $3 .{ }^{\circ} »$, ob. cit., p. 134; Riera TÁBOAS, A. et. al.: «Prueba de las causas modificadoras de la imputabilidad», ob. cit., p. 2. En este sentido, FonseCA MORALEs hace referencia a la falta de reflexión y a la incapacidad de dirigir y controlar adecuadamente la acción. En Exención y atenuación de la responsabilidad criminal..., ob. cit., p. 139. 
pueda operar como contramotivo, como elemento a valorar de forma adecuada por el sujeto en el proceso de deliberación. Y, en segundo lugar, tiene que ser capaz de inhibir, de omitir dicho comportamiento comprendido como ilícito y orientar su conducta hacia lo prescrito por las normas, capaz de llevar a cabo un comportamiento conforme a derecho, aunque finalmente haya decidido no hacerlo ${ }^{89}$.

En mi opinión, esta postura es la más adecuada puesto que contempla las fases que, según se ha visto, configuran el proceso volitivo, el proceso que tiene como resultado un acto libre y voluntario.

Como se ha señalado en relación con la capacidad de comprender la ilicitud del hecho, para declarar a un sujeto imputable, el Código Penal no exige que este, efectivamente, haya decidido no llevar a cabo el hecho ilícito y, finalmente, no lo haya realizado, sino que basta con la posibilidad de todo ello, es decir, basta con que, en el momento de los hechos, haya tenido la capacidad de decidir y actuar en un sentido distinto a la comisión del hecho ilícito, lo que plantea la cuestión de cuáles son las funciones psíquicas que condicionan dicha capacidad.

En la bibliografía consultada suele hacerse referencia, en sentido negativo, a los supuestos en los cuales un sujeto no puede actuar conforme a la comprensión de la ilicitud del hecho, incluyendo aquellos en los cuales debido a defectos en los frenos inhibitorios, el sujeto es incapaz de dominar sus impulsos, de controlar sus acciones y de acomodar su conducta a las exigencias del orden jurídico establecido ${ }^{90}$; se trata de supuestos en los cuales la voluntad (entendida en sentido estricto) está alterada.

Ahora bien, teniendo en cuenta que a toda actuación le preceden las fases de concepción, deliberación y decisión; que la capacidad de actuar conforme a la comprensión de la ilicitud del hecho integra la capacidad de alcanzar

${ }^{89}$ Fonseca Morales, G. M.: Exención y atenuación de la responsabilidad criminal..., ob. cit., p. 31; GARCÍA GARCÍA, J.: Drogodependencias y justicia penal, ob. cit., p. 132; Naquira Riveros, J.: «Imputabilidad, conciencia de lo injusto...», ob. cit., pp. 151 y 152; Quintero Olivares, G.: Parte General del Derecho Penal, ob. cit., p. 558.; UrrueLA MorA, A.: Imputabilidad penal..., ob. cit., p. 178.

Acertadamente señala MARTínez Arrieta que se trata de dos caras de la misma moneda, puesto que la capacidad que estamos analizando se presenta con un doble contenido, en sentido positivo consiste en la capacidad de actuar conforme a la comprensión de la norma, y en sentido negativo, en la capacidad de inhibirse ante una posibilidad de actuar contra la norma. En «Tratamiento penal de las circunstancias...», ob. cit., p. 323.

${ }^{90}$ Carrasco Gómez, J. J./Maza Martín, J. M.: Tratado..., ob. cit., p. 295 y ss.; CARRASCO GÓmEZ, J. J.: «Circunstancias psíquicas...», ob. cit., p. 158; FonseCA Morales, G. M.: La anomalía o alteración psíquicas ..., ob. cit., p. 50; MAZA MARTín, J. M.: «Arts. 20.1. $.^{\circ},{ }^{\circ}{ }^{\circ}$ y $3 .^{\circ} »$, ob. cit., p. 147; RIERA TÁBOAS, A. et. al.: «Prueba de las causas modificadoras de la imputabilidad», ob. cit., p. 2; SERRANO ButragueÑo, I.: «Art. 20», ob. cit., p. 364. 
dicha comprensión; y que esta capacidad, como se ha indicado antes, depende de todas las funciones que conforman el psiquismo humano excepto la voluntad, hay que concluir que la alteración de cualquiera de las funciones psíquicas a las que nos estamos refiriendo (afectividad, atención, conciencia, inteligencia, memoria, pensamiento, percepción y voluntad) va a condicionar la capacidad de actuar conforme a la comprensión de la ilicitud del hecho y, por tanto, disminuir o anular la imputabilidad del individuo.

Ya se ha señalado al comienzo de este apartado que es frecuente referirse a esta capacidad de actuar con las expresiones «elemento volitivo» de la imputabilidad o «capacidades volitivas»» ${ }^{91}$. En mi opinión, la utilización de las mismas puede hacerse con la siguiente cautela: las facultades cognitivas o cognoscitivas, como indiqué, son las implicadas en el proceso de comprensión, y se incluyen todas las funciones psíquicas ya conocidas excepto la voluntad (en sentido estricto); si se utiliza la expresión «facultades volitivas» para referirnos a las que intervienen en la capacidad de actuar, nos estamos refiriendo a todas las funciones psíquicas conocidas, incluida la voluntad, pero no sólo a ella.

\subsection{Compatibilidad con el concepto de imputabilidad propuesto en esta investigación}

Una vez expuesto el significado de las expresiones «comprender la ilicitud del hecho y actuar conforme a esa comprensión» recogidas en los arts. 20.1 y 20.2 del CP, estamos en condiciones de analizar la compatibilidad del concepto de imputabilidad propuesto con el que se desprende del texto legal.

Según la postura defendida en este trabajo, el juicio de imputabilidad se basa en el análisis de las funciones psíquicas que intervienen en el concreto proceso volitivo que ha dado lugar al hecho ilícito que se quiere imputar a un sujeto, en el cual se suceden las fases de concepción, deliberación, decisión y ejecución. Estas funciones, como ya sabemos, son la afectividad, la atención, la conciencia, la inteligencia, la memoria, el pensamiento, la percepción y la voluntad, de manera que si ninguna de ellas está alterada, el sujeto será imputable, mientras que, si sufren algún tipo de perturbación que condicione dichas fases, el acto finalmente llevado a cabo no es plenamente libre o voluntario, y habrá que afirmar que el sujeto es inimputable o que su imputabilidad está disminuida, siempre que dicho supuesto esté recogido en la regulación penal.

El Código Penal exige, en primer lugar, que el sujeto sea capaz de comprender la ilicitud del hecho, capacidad que, como acabamos de ver, exige la intervención de todas las funciones citadas excepto la voluntad. En mi opi-

${ }^{91}$ Carrasco Gómez, J. J.: «Circunstancias psíquicas...», ob. cit., p. 158. 
nión, este proceso de comprensión se corresponde con las fases de concepción y deliberación del proceso volitivo, fases en las cuales también intervienen todas las funciones psíquicas conocidas, salvo la voluntad, entendida en sentido estricto.

En segundo lugar, es necesario que el sujeto sea capaz de actuar conforme a esa comprensión, es decir, de decidir no llevar a cabo el hecho ilícito y de, finalmente, inhibirlo, capacidad ésta en la que intervienen todas las funciones psíquicas incluida (ahora sí) la voluntad. No creo que le cueste mucho al lector identificar el contenido de esta capacidad con las fases de deliberación y ejecución del proceso volitivo, en las cuales, como ya sabemos, también intervienen todas las funciones psíquicas.

En conclusión, podemos afirmar que el concepto de imputabilidad defendido es perfectamente compatible con el que se desprende de la regulación penal vigente. La comprensión de la ilicitud del hecho y la actuación conforme a esa comprensión se identifican con las fases del proceso volitivo y las funciones psíquicas que afectan a esas capacidades de comprensión y actuación, son las mismas que intervienen en el proceso volitivo y permiten afirmar que el acto consecuencia del mismo es libre y voluntario.

\subsection{Algunas críticas no compartidas}

En este apartado me voy a referir, de manera muy breve, a dos críticas que suelen hacerse a la redacción del Código Penal y que, después de la exposición llevada a cabo en las paginas precedentes, considero que no están justificadas.

Un amplio sector doctrinal critica la redacción de los arts. 20.1 y 20.2 del Código penal al considerar que el legislador ha reducido el análisis de la imputabilidad al examen de dos funciones psíquicas, la inteligencia y la voluntad, de manera que se desprecian otro tipo de procesos y funciones psíquicas que intervienen en la conducta humana y se desconoce que dichas funciones no actúan como módulos independientes sino como un todo ${ }^{92}$.

${ }^{92}$ Cabrera Forneiro, J./Fuertes Rocañín, J. C: Psiquiatría y Derecho:..., ob. cit., p. 155; CARMONA SAlGADO, C.: «Causas de inimputabilidad: alteración de la percepción», en Pantoja García, F./Bueno Arús, F. (dirs.): Actual doctrina de la imputabilidad penal, Estudios de Derecho Judicial, n. 110, CGPJ, Madrid, 2006, pp. 468 y 469; CASTELló NiCÁs, N.: «Exención y atenuación...», ob. cit., p. 306; LA MISMA: «Artículo 20.1», ob. cit., p. 122; LA MISMA: La imputabilidad penal del drogodependiente, ob. cit., p. 67; ESBEC RoDRíGUEZ, E./ Delgado BuEnO, S.: «Imputabilidad: concepto y perspectivas...», ob. cit., p. 322; IgLesIAS RIo, M. A.: «La eximente de «anomalía o alteración psíquica». (Art. 20-1 CP). Una problemática abierta hacia el futuro científico», ADPCP, Vol. LVI, 2003, p. 162; MARCó RIBÉ, J./ Martí Tusquets, J. L.: Psiquiatría Forense, ob. cit., p. 418; Mateo Ayala, E. J.: La imputabilidad del enfermo psíquico: un estudio de la eximente de anomalía o alteración psíquica en el Código Penal español, Instituto de Criminología de Madrid-Editoriales de Derecho 
Después de las conclusiones a la que se ha llegado a lo largo de este trabajo, es evidente que no se comparte esta crítica. En primer lugar, el legislador no ha limitado el contenido de la imputabilidad al análisis de la inteligencia y la voluntad. El Código Penal se refiere a la capacidad de comprender la ilicitud del hecho y de actuar conforme a esa comprensión, no a las funciones psíquicas intervinientes en estos procesos. Y, en segundo lugar, tal y como se interpretan aquí los arts. 20.1 y 20.2, dichas capacidades exigen la intervención de todas las funciones psíquicas en las que se divide la psique humana, no sólo la inteligencia y la voluntad ${ }^{33}$.

La segunda crítica que quiero mencionar hace referencia al hecho de que, en opinión de algunos autores, el concepto de imputabilidad que se deduce de los citados preceptos impide tener en cuenta la influencia que los factores socioculturales pueden tener en las capacidades de comprensión y actuación de los individuos ${ }^{94}$.

En mi opinión, la redacción del Código Penal no impide la valoración de estos factores en la imputabilidad lo que no obsta para que, tal y como se defiende en esta investigación, sea más conveniente no hacerlo.

En los procesos de comprensión y actuación, como ya se ha afirmado en más de una ocasión, inciden y tienen repercusión los factores socioculturales; la redacción del Código Penal no impide considerar que dichos factores deben ser objeto de análisis en la imputabilidad siempre que, en el caso concreto hayan impedido al sujeto comprender la ilicitud del hecho o actuar conforme a esa comprensión. Cuestión distinta es que se opte por no dar relevancia

reunidas, Madrid, 2003, pp. 80 y 134; Muñoz Conde, F./García Arán, M.: Derecho Penal. Parte General, ob. cit., p. 368; PorTERo LAZCANO, G.: «Patología dual. Imputabilidad», inédito, materiales entregados en el Máster Universitario en Drogodependencias y otras adicciones, Universidad de Deusto, Bilbao, curso 2010-2011, pp. 18 y ss.; EL MISMO: «Valoración médico forense de la enfermedad mental», Eguzkilore, n. 10, 1996, p. 142; SUÁREZ-MIRA RodríGuez, C.: La imputabilidad del consumidor de drogas, ob. cit., p. 96.

93 De la misma opinión, FonseCA Morales, G. M.: La anomalía o alteración psíquica..., ob. cit., p. 53.

94 CAParrós SÁnchez, N.: «La imputabilidad del psicópata», en Labrador, F. J. (dir.): Aportaciones de la Psicología al ámbito jurídico, Cuadernos de Derecho Judicial, n. 19, CGPJ, Madrid, 1994, p. 175; DíEz RIPOLLÉS, J. L.: Los elementos subjetivos del delito..., ob. cit., p. 294; García BlázQuez, M.: Análisis médico-legal de la imputabilidad..., ob. cit., pp. 42 y ss.; MARTínEZ ARRIETA, A.: «Tratamiento penal de las circunstancias...», ob. cit., p. 321 y ss.; MORALES GARCÍA, O.: «Inimputabilidad y enajenación mental», Cuadernos Jurídicos, n. 13, 1993, p. 68; Muñoz Conde, F./García Arán, M.: Derecho Penal. Parte General, ob. cit., pp. 362 y ss.; Muñoz Conde, F./Heredia MartíNEZ, F.: «La imputabilidad en la perspectiva de la actual legislación», ob. cit., p. 87; NAQUIRA RIVEROS, J.: «Imputabilidad, conciencia de lo injusto...», ob. cit., pp. 142 y ss.; PAdilla Alba, H. R.: «El fundamento de la capacidad de culpabilidad...», ob. cit., p. 956; EL MISMO: Exención y atenuación ..., ob. cit., p. 104; SuÁrEZ-Mira RodríGUEZ, C.: La imputabilidad del consumidor de drogas, ob. cit., pp. 79 y 97. 
a estos factores en este elemento del delito salvo que, indirectamente, afecten a las funciones psíquicas del sujeto, pero, repito, es la interpretación que considero más adecuada, no la única posible dada la regulación vigente.

TITLE: A review of the concept of imputability from the health sciences. Compatibility with the criminal law in force.

RESUMEN: La imputabilidad es una categoría del delito intimamente vinculada a las capacidades ofunciones psíquicas de los individuos. Siendo esto así, parece obvia la necesidad de que las aportaciones y conocimientos de las ciencias que estudian estas capacidades y funciones sean tenidas en cuenta a la hora de configurar el fundamento y contenido de esta categoría del delito. No es esta, sin embargo, la práctica común entre los penalistas que se ocupan del estudio de la misma. En este artículo se va a proponer un concepto de imputabilidad, cuyo fundamento es un indeterminismo limitado, que toma en consideración dichas aportaciones y conocimientos. Este concepto es, a su vez, compatible con el que se deduce de la regulación penal vigente.

PALABRAS CLAVE: imputabilidad, funciones psíquicas, proceso volitivo, capacidad para comprender, capacidad para actuar.

ABSTRACT: The imputability is an element of the offence closely linked to psychic abilities and capacities of individuals. If this is so, it seems obvious the need to take into account the contribution and knowledge of sciences that study these abilities when setting the basis and content of this element. This is not, however, common practice among jurist who deal with it. This article proposes a concept of imputability which basis is a limited indeterminist that take into account such contributions and that is compatible with the concept of imputability deduced from the criminal law in force.

KEY WORDS: imputability, psychic abilities, volitional process, capacity to understand, capacity to act. 